GRASAS Y ACEITES 66 (1)

January-March 2015, e064

ISSN-L: 0017-3495

doi: http://dx.doi.org/10.3989/gya.0692141

\title{
Fatty acid composition of soybean/sunflower mix oil, fish oil and butterfat applying the AOCS Ce 1j-07 method with a modified temperature program
}

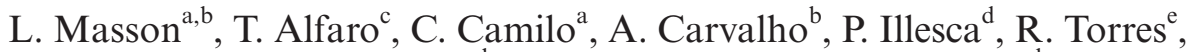 \\ M. Tavares do Carmo ${ }^{\mathrm{b}}$, J. Mancini-Filho ${ }^{\mathrm{e}}$ and C. Bernal ${ }^{\mathrm{d}, \varpi}$ \\ ${ }^{a}$ Centro de Investigación y Desarrollo en Grasas y Aceites - CIDGRA, Universidad de Chile, Santiago, Chile \\ ${ }^{\mathrm{b}}$ Instituto de Nutrição Josué de Castro, Universidade Federal do Rio de Janeiro, Rio de Janeiro, Brasil \\ ${ }^{\mathrm{c}}$ Instituto Costarricense de Investigación y Enseñanza en Nutrición y Salud (INCIENSA), San José, Costa Rica

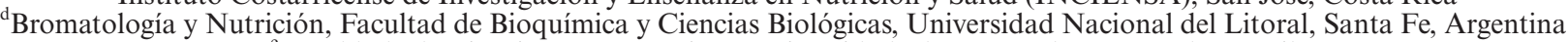 \\ ${ }^{e}$ Faculdade de Ciências Farmacêuticas, Universidade de São Paulo, São Paulo, Brasil \\ Corresponding autor: cbernal@fbcb.unl.edu.ar
}

Submitted: 05 June 2014; Accepted: 15 October 2014

SUMMARY: Gas-Liquid Chromatography (GLC) methods such as AOAC Fat in foods 966.06 (2005), AOCS Official Methods Ce 1h-05 (2005), Ce 1j-07 (2007), allow for analyzing the fatty acids (FAs) in dietary fats using highly polar liquid phase capillary columns. However, there are still difficulties in completely separating butiric acid from solvent, FA critical pairs with similar polarity, conjugated linoleic acid (CLA) isomers, and long chainpolyunsaturated FAs (LC-PUFAs). Therefore, the selection of the temperature program to be employed is important. This work aimed to improve the AOCS Ce 1j-07 Method for the FA composition of a mixture of soybean and sunflower oil, fish oil, and butterfat, using a modified temperature program, tested among five laboratories. It takes more time, but it allows to completely separate butyric acid from the solvent, trans-18:1 from cis-18:1, 20:1 isomers from 18:3 n-3, 22:1 n-9 from 20:4 n-6, 20:5 n-3 from 24:0 and the main CLA isomers, thus permitting FA quantification in fats and oils for different purposes such as nutritional labeling, quality control and research.

KEYWORDS: AOCS Ce 1j-07 Method; Butterfat; Fatty acid composition; Fish oil - Soybean/sunflower oil mixture

RESUMEN: Composición en ácidos grasos de mezcla de aceite de soja y girasol, aceite de pescado y mantequilla por el método AOCS Ce 1j-07 usando un programa de temperatura modificado. Métodos por cromatografía gas-líquido, AOAC 966.06 (2005), AOCS Ce 1h-05 (2005), Ce 1j-07 (2007) permiten determinar ácidos grasos (AG) en matrices grasas usando columnas capilares altamente polares y distintos programas de temperatura. No obstante, aún existen dificultades para separar ácido butírico del solvente, pares críticos de AG con polaridades similares, isómeros del ácido linoleico conjugado (CLA), AG de cadena larga poliinsaturados (LC-PUFAs). El objetivo fue mejorar el Método AOCS Ce 1j-07 aplicándolo a la composición en AG de mezcla de aceite soja/girasol, aceite de pescado, mantequilla, usando un programa de temperatura modificado, entre cinco laboratorios. El programa de temperatura elegido, si bien emplea más tiempo, permite separar completamente ácido butírico del solvente, trans-18:1 de cis-18:1, isómeros 20:1 de 18:3 n-3, 22:1 n-9 de 20:4 n-6, 20:5 n-3 de 24:0, los principales isómeros CLA. Esta propuesta permite cuantificar AG con diferentes propósitos, entre ellos, etiquetado nutricional, control de calidad e investigación.

PALABRAS CLAVE: Aceite de pescado; Aceite de soja/girasol; Composición en ácidos grasos; Mantequilla; Método AOCS Ce $1 j-07$

Citation/Cómo citar este artículo: Masson L, Alfaro T, Camilo C, Carvalho A, Illesca P, Torres R, Tavares do Carmo M, Mancini-Filho J, Bernal C. 2015. Fatty acid composition of soybean/sunflower mix oil, fish oil and butterfat applying the AOCS Ce 1j-07 method with a modified temperature program. Grasas Aceites 66 (1): e064. doi:http://dx.doi. org/10.3989/gya.0692141.

Copyright: (C) 2015 CSIC. This is an open-access article distributed under the terms of the Creative Commons Attribution-Non Commercial (by-nc) Spain 3.0 Licence. 


\section{INTRODUCTION}

The analysis of fatty acids (FAs) is required for many applications in food science such as nutritional labeling, quality control, composition databases, traceability for international markets, nutrition and health, medical purposes and research. The method for analyzing FAs should include the maximum resolution and identification of FAs, covering from short chain to long chain FAs, saturated (SFAs), monounsaturated (MUFAs), polyunsaturated (PUFAs), long chain-PUFAs (LC-PUFAs), as well as positional and geometrical FA isomers, naturally or industrially produced. The main procedures for FA analysis in different matrixes are based on GLC methods (Seppänen-Laakso et al., 2002; Christie et al., 2007; Smith and Hansen, 2008; Mossoba and Kramer, 2009). Complementary techniques such as thin-layer chromatography impregnated with silver nitrate and silver-ion liquid chromatography (Kramer et al., 1998), Fourier transform infrared spectroscopy (Van de Voort et al., 2008; Mossoba et al., 2009), and mass spectrometry (Ratnayake, 2004; Manzano et al., 2012) are also used.

The identification and quantification of SFAs, MUFAs, PUFAs, LC-PUFAs, trans-FA (TFA) isomers by direct GLC has been improved in recent years using high efficiency silica capillary columns, $100 \mathrm{~m}$ coated with not bonded highly polar stationary liquid phase $100 \%$ cyanopropyl polysiloxane, such as SP-2560, CP Sil 88, Rtx-2560 (Mossoba and Kramer, 2009). However, using these columns, certain difficulties still exist to completely separate short chain FAs such as butyric acid from the peak solvent, some critical pairs with similar polarity, conjugated linoleic acid (CLA) isomers present in ruminant fats (Mossoba and Kramer, 2009), along with the identification and quantification of LC-PUFAs mainly with different positions and the quantity of double bonds in fish oils (Kramer et al., 2008). Thus, the selection of GLC parameters such as the temperature program is analytically very important and it mainly depends on the complexity of the FAs present in the sample and the purpose of the analysis. These issues must be known by the analyst, and good reviews on these topics are available in the literature (Seppäenen-Laakso et al., 2002; Kramer et al., 2004; Ratnayake et al., 2006; Destaillats et al., 2007; Rozema et al., 2008; Mossoba and Kramer, 2009; Ruiz-Rodriguez et al., 2010). There are also several standardized methods such as: AOAC Fat in foods 966.06 (2005), AOCS Official Method Ce 1h-05 (2005), AOCS Official Method Ce 1j-07 (2007), AOCS Official Method Ce 2b-11 (2011) and AOCS Official Method Ce 2c-11 (2011). They use GLC, considering direct or previous fat extraction, with differences in stationary liquid phases, internal standards, and procedures to prepare FA methyl esters (FAMEs). When the conditions of direct GLC are not sufficient for a good separation, combined methodologies must be used (Kramer et al., 2008).

The aim of this study was to improve Method AOCS Ce $1 \mathrm{j}-07$, using a modified temperature program, for identifying and quantifying a wide spectrum of FAs present in a sample of soybean and sunflower mixed oil, fish oil and butterfat. It takes more time, but it allows for a complete separation of butyric acid from the solvent, trans-18:1 from cis$18: 1,20: 1$ isomers from $18: 3 n-3,22: 1$ n-9 from 20:4 $\mathrm{n}-6,20: 5 \mathrm{n}-3$ from 24:0, the main CLA isomers. This proposal permits FA quantification in fats and oils for different purposes such us nutritional labeling, quality control, and research.

\section{MATERIALS AND METHODS}

\subsection{Standards, chemicals and samples}

Internal standard (IS) Tritridecanoine [13:0triacylglycerol (TAG)], external standards GLC-463 Reference Standard containing 52 FAME mixture (purity $>99 \%$ ) and trans-mix GLC 481 (purity $>99 \%$ ) were purchased from $\mathrm{Nu}-\mathrm{Chek}(\mathrm{Nu}-\mathrm{Ch}$ ek Prep, Inc., Elysian, MN, USA). Beef-Pork Fat Blend Certified Reference Material ( $\mathrm{N}^{\circ} 1061$, BCR 163) was purchased from the Joint Research Center, Institute for Reference Materials and Measurements (IRMM, Geel, Belgium). Linoleic acid methyl esters, cis/trans mix (Catalog n 47791); FAME mix: C4-C24 unsaturated (Catalog $\left.\mathrm{N}^{\circ} 18919\right)$ and individual FAMEs from $4: 0$ to $24: 1$ chain length saturated and unsaturated were obtained from Supelco (Bellefonte, PA, USA). GLC-463 standard dissolved in hexane $\left(20 \mathrm{mg} \cdot \mathrm{mL}^{-1}\right)$ was used for calculating the empirical correction factors (ECFs) for each one of its 52 FAMEs and for the fat samples' FAME identification, together with other FAME standards. The IS, 13:0-TAG prepared in hexane $\left(5 \mathrm{mg} \cdot \mathrm{mL}^{-1}\right)$ was used for calculating $\mathrm{g}$ FAME $100 \mathrm{~g}^{-1}$ FAME according to the AOCS Method Ce 1j-07. N-Hexane HPLC grade; sodium chloride p.a.; sodium sulfate anhydrous p.a.; sodium hydroxide p.a.; methanol p.a. Merck (Hohenbrunn, Germany), $\mathrm{BF}_{3} 14 \%$ in methanol Sigma-Aldrich (St. Louis, MO) were used.

The fat samples were selected according to their different FA compositions and were purchased from local commercial sources: a) Refined mixture of soybean and sunflower oil (80/20), (Santa Fe, Argentina); b) butterfat (Santa Fe, Argentina); c) fish oil soft gel capsules (Santiago, Chile).

The fat samples, the same lots of FAME standards and BCR 163 reference material were distributed among the five participating laboratories from the following institutions: Universidad Nacional del Litoral (UNL), Santa Fe, Argentina; Universidade Federal do Rio de Janeiro (UFRJ), Río de Janeiro, 
Brazil; Universidade de São Paulo (USP), São Paulo, Brazil; Universidad de Chile (UCH), Santiago, Chile and INCIENSA, Ministerio de Salud, San José, Costa Rica. All these materials were maintained at $-23{ }^{\circ} \mathrm{C}$ until they were analyzed.

\subsection{Other materials}

New fused silica capillary columns $\mathrm{SP}^{\mathrm{TM}}-2560$ $0.25 \mathrm{~mm}$ i.d. $\times 100 \mathrm{~m}$ length, coated with $100 \%$ cyanopropyl polysiloxane stationary phase, film thickness $0.20 \mu \mathrm{m}$, were used in four laboratories (Supelco, Inc., Bellefonte, PA, USA, Part $\mathrm{N}^{\circ}$ 24056), one laboratory used $\mathrm{CP} \mathrm{Sil}{ }^{\mathrm{TM}} 88$ with the same characteristics (Varian, Walnut Creek, CA, USA, Part N ${ }^{\circ}$ CP7489). Focus Liner with glass wool (Catalog $\mathrm{N}^{\circ} 21022$ 211.5, Restek or equivalent Supelco, Sigma-Aldrich, St. Louis, MO), and capped test tubes Pyrex USA, $\mathrm{N}^{\circ}$ 9826, with teflon liner, $150 \mathrm{~mm} \times 20 \mathrm{~mm}$ (Fisher Scientific Corp., USA) were used. The following gases were employed: as carrier gas helium or hydrogen, as make up gas of nitrogen, hydrogen and air for the flame ionization detector (FID) of chromatography quality.

\subsection{Instrumentation and analytical conditions}

The GLC instruments located at the five laboratories from the participating institutions were the following: UNL/Argentina: Shimadzu GC 2014 with GC Solutions software; UFRJ/Brazil: Agilent 7890 A and EZ Chrom Elite; USP/Brazil: Shimadzu GC 17A and Class GC 10; UCH/Chile: HP 5890 Serie II and Clarity Chromatography SW Data Apex 2006, Waters; INCIENSA/Costa Rica: Agilent 7890 A with Chemstation Agilent, with FID detector (air to hydrogen ratio, 400:40). The injector and detector temperatures were maintained at $250{ }^{\circ} \mathrm{C}$, split ratio $1: 100,1 \mu \mathrm{L}$ of standard or sample, equivalent to $20 \mu \mathrm{g}$ of total FAMEs were injected using an autosampler device in each GLC run. The fluxes of hydrogen and helium were $1 \mathrm{~mL} \cdot \mathrm{min}^{-1}$ and $2 \mathrm{~mL} \cdot \mathrm{min}^{-1}$, respectively, the nitrogen flux as make up gas was $25 \mathrm{~mL} \cdot \mathrm{min}^{-1}$.

\subsection{Correction factors}

The theoretical correction factor (TCFr) relative to the IS (13:0-TAG) was used to correct the FID response for the quantitative expression of each FAME (g FAME $100 \mathrm{~g}^{-1}$ FAME). The TCFr for short chain FAs and LC-PUFAs did not show a proper quantitative response by FID, with the real possibility of underestimating short chain FAs or to overestimate LC-PUFAs. Then, each laboratory experimentally determined the empirical correction factor (ECF) for each one of the 52 FAMEs present in GLC 463, from butyric acid to DHA, using g $\%$ and $\%$ purity indicated in the Certificate of
Analysis. These calculated ECFs were used for the FAMEs quantification in the Reference Certified Material BCR 163, and in the commercial samples. Even the Reference Standard GLC 714 is recommended by the AOCS Official Method Ce 1j-07 (2007); Reference Standard GLC 463 has been used for its important comparative advantages: it contains 52 FAMEs with a wide spectrum of FAs from 4:0 to $24: 1$, most of them present in the fat matrixes analyzed in this study. The FAMEs are in different percentages, $1 \%, 2 \%$ and $4 \%$, including critical pairs with close polarity, which permits a good separation, clear identification according to their respective relative retention times to 18:0 in SP-2560 and CP Sil 88 columns and their quantification. Standard mixture GLC 714 has only 24 FAMEs, and is missing key FAMEs, such as 4:0, 5:0, 6:0, which are fundamental for the butterfat analysis.

\subsection{BCR-163 certified reference material, identification and quantification}

In order to check the quantitative performance of the modified temperature program, the seven certified FAMEs were quantified and compared, including as appropriate their positional and geometric isomers present in the BCR-163 certified reference material using the calculated ECF and tabulated TCFr. The percentage of recovery for each certified FAME was calculated by each laboratory considering the analytical value obtained and the certified value declared by the Institute for Reference Materials and Measurements (Geel, Belgium).

In accordance with the procedure of the AOCS Official Method Ce 1j-07 (2007), $1 \mathrm{~mL}$ of the IS TAG $13: 0$ solution containing $5 \mathrm{mg}$ was added to $0.100 \pm 0.001 \mathrm{~g}$ of BCR-163 and weighed at least in triplicate. For identification, the relative retention time of each FAME to 18:0 was used, and compared with those obtained for the FAMEs present in GLC 463, and literature references.

\subsection{Fat samples: quantification, derivatization and identification of fatty acids}

To $0.100 \pm 0.001 \mathrm{~g}$ of each anhydrous fat samples, soybean and sunflower oil mixture $1(80 / 20)$, fish oil and butterfat, $1 \mathrm{~mL}$ of the IS solution containing $5 \mathrm{mg}$ of 13:0-TAG was added, followed by the FAME derivatization procedure using $\mathrm{BF}_{3} 14 \%$ in methanol according to International Standards ISO 5509 (2000), indicated by the AOCS Method Ce $1 \mathrm{j}-07$. The FAMEs in the fat samples were identified by the GLC procedure using the modified temperature program, by comparison of their relative retention times calculated to $18: 0$ with the respective relative retention times of the 52 FAMEs in the GLC-463 standard, other reference FAME 
materials mentioned in 2.1 and in the literature. The results for the soybean/sunflower oil mixture were determined using its respective calculated ECF and tabulated TCFr values. For fish oil and anhydrous butterfat only ECF values were used for the quantitative procedure. The final results were expressed in $\mathrm{g}$ FAME $100 \mathrm{~g}^{-1}$ FAMEs, g FA/100 g FAs and TAG equivalents $\%$ (TAGe), according to the AOCS Method Ce 1j-07 (2007).

\subsection{Statistical analysis}

In the five laboratories, the $\mathrm{z}$ score was calculated for each one of the seven certified FAMEs of the reference certified material BCR 163, using their respective calculated ECF, according to IUPAC (Thompson et al., 2006). ANOVA statistical analysis at $95 \%$ confidence was used for testing if there were significant differences among the values obtained for the certified FAMEs using ECF and TCFr and applying the Statgraphics Plus 5.1 statistical program.

\section{RESULTS AND DISCUSSION}

\subsection{Temperature program and GLC checking performance}

The AOCS Ce 1j-07 (2007) initial isotherm temperature program, i.e. $180{ }^{\circ} \mathrm{C}$ (held for $32 \mathrm{~min}$ ), icreased at a rate of $20^{\circ} \mathrm{C} \cdot \mathrm{min}^{-1}$ to $215^{\circ} \mathrm{C}$ (held for $31.25 \mathrm{~min}$ ), for a total time $50 \mathrm{~min}$ was assayed running the GLC 463 standard. Figure 1A shows the best chromatogram obtained. In general, 51 peaks of the 52 FAMEs were detected. The short chain FAMEs, including butyric acid, eluted very close to the solvent peak, and in some of the five participant laboratories (data not shown) it could not be separated completely from the solvent peak; 20:5 n-3 emerged together with 24:0, and overlapping of some critical FA pairs was observed. These analytical difficulties were considered of importance to modify the temperature program, because butterfat and fish oil were part of the test samples analyzed in this study. Mild temperature conditions at the beginning of the GLC run, slower rate temperature in the middle zone and speeding the elution of the LC-PUFAs at the end of the run were tested. After assaying different approaches, the following temperature program was selected and assayed among the five laboratories: an initial temperature of $100{ }^{\circ} \mathrm{C}$ increased at a rate of $3{ }^{\circ} \mathrm{C} \cdot \mathrm{min}^{-1}$ to $140^{\circ} \mathrm{C}$, at a rate of $0.5^{\circ} \mathrm{C} \cdot \mathrm{min}^{-1}$ to $170{ }^{\circ} \mathrm{C}$, increased ar a rate of $4{ }^{\circ} \mathrm{C}$ per $\mathrm{min}^{-1}$ to $220{ }^{\circ} \mathrm{C}$, and maintained for $30 \mathrm{~min}$. This modified temperature program optimized the separation of the 52 FAMEs present in GLC 463, and took 110 min, as can be clearly observed in Figure 1B.

Even considering this longer chromatographic run, the positive results obtained with this modified temperature program permitted a clear resolution for very short chain FAs. Butyric acid became quite separated from the peak of solvent, and the overlapping of critical pairs was properly resolved, such as 14:1 with 15:0, 15:1 with 16:0, trans and cis 18:1 isomers; 18:2 n-6 isomers; 20:1 isomers from $18: 3 n-3 ; 20: 0$ from $18: 3 n-3 ; 22: 0$ from $20: 3$ n-3; 22:1 n-9 from 20:4 n-6, 20:5 n-3 from 24:0. In addition, odd and even carbon chain-FAs, were well separated. With respect to the GLC checking performance, the partition obtained with this modified GLC temperature program was complete between the base line of $9 c-18: 1$ and $11 c-18: 1$, and the resolution was close to 1.0 between $11 c-20: 1$ and $9 c, 12 c, 15 c-18: 3$. Therefore, this good resolution of the 52 FAMEs throughout the chromatographic run allows for the use of this modified temperature program for FA identification and quantification in a wide variety of foods, including dairy products, animal fats, vegetable and fish oils, with a complex FA composition, maintaining the general procedure described in the AOCS Method Ce 1j-07 (2007).

The analytical performance of the capillary columns $\mathrm{SP}^{\mathrm{TM}}-2560$ or CP Sil ${ }^{\mathrm{TM}} 88$ used in this study yielded similar analytical results with hydrogen or helium as carrier gas.

\subsection{Correction factors}

The values obtained for the ECF determined experimentally by the five laboratories for each one of the 52 FAMEs in GLC 463 are presented in Table 1 . They were compared with the respective tabulated TCFr. The difference obtained between both values was expressed as a \% according to the AOCS Official Method Ce 1j-07 (2007) formula. Important differences between ECF and TCFr values were obtained in the extremes for short chain FAs and LC-PUFAs, confirming that for fats containing these types of FA, determined ECF values must be used (Mossoba and Kramer, 2009). In addition, the AOCS Method Ce 1j-07 (2007) does not provide TCFr for 20:3, 20:4, 20:5, 22:5 and 22:6 FAMEs, and therefore calculated ECF must be used. The ECF values for FAMEs of 8-12 carbon atoms showed a more homogeneous tendency. For medium chain FAs, mainly saturated with 14-18 carbons, the difference between both values was lower than 3\%, confirming that the GLC systems of the five laboratories worked properly. The ECF data corresponded to the mean value obtained from triplicates.

\subsection{BCR-163 certified reference material}

A total of 49 FAMEs were identified and quantified in the reference standard BCR-163; 26 FAMEs corresponded to the seven certified 

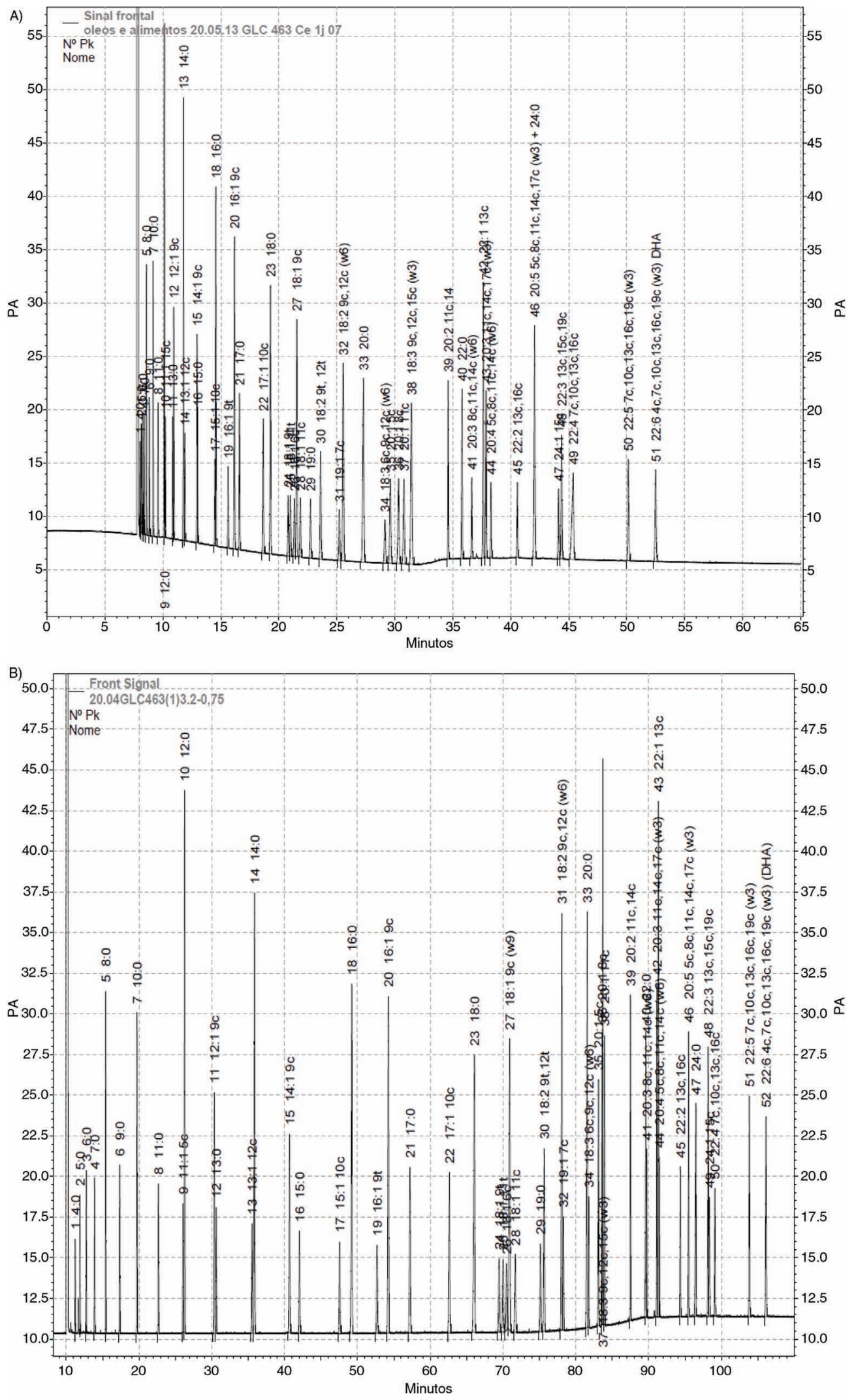

FIGURE 1. A. Representative chromatogram of GLC 463 Certified Reference Standard using the AOCS Official Method Ce 1j-07. B. Representative chromatogram of GLC 463 Certified Reference Standard using the proposed temperature program (see paragraph 3.1 for operating conditions). 
TABLE 1. Comparison of ECF vs. TCFr values for the 52 FAMEs of the GLC-463 Reference Material

\begin{tabular}{|c|c|c|c|c|c|c|c|c|c|c|c|}
\hline \multirow[b]{2}{*}{ FAME } & \multirow[b]{2}{*}{ TCFr } & \multicolumn{2}{|c|}{ Lab 1} & \multicolumn{2}{|c|}{ Lab 2} & \multicolumn{2}{|c|}{ Lab 3} & \multicolumn{2}{|c|}{ Lab 4} & \multicolumn{2}{|c|}{ Lab 5} \\
\hline & & ECF & $\Delta(\%)$ & ECF & $\Delta(\%)$ & ECF & $\Delta(\%)$ & ECF & $\Delta(\%)$ & ECF & $\Delta(\%)$ \\
\hline $4: 0$ & 1.4534 & 1.6450 & 13.2 & 1.7302 & 19.0 & 2.3807 & 63.8 & 1.9436 & 33.7 & 2.4265 & 67.0 \\
\hline $5: 0$ & 1.3224 & 1.4550 & 10.1 & 1.4328 & 8.3 & 1.5614 & 18.1 & 1.6213 & 22.6 & 1.8000 & 36.1 \\
\hline $6: 0$ & 1.2351 & 1.4060 & 13.9 & 1.3053 & 5.7 & 1.3169 & 6.6 & 1.4835 & 20.1 & 1.5540 & 25.8 \\
\hline 7:0 & 1.1727 & 1.3510 & 15.3 & 1.3326 & 13.6 & 1.3621 & 16.1 & 1.4049 & 19.8 & 1.4101 & 20.2 \\
\hline $8: 0$ & 1.1259 & 1.1740 & 4.3 & 1.1639 & 3.4 & 1.1696 & 3.9 & 1.1988 & 6.5 & 1.1944 & 6.1 \\
\hline 9:0 & 1.0896 & 1.1440 & 5.0 & 1.1177 & 2.6 & 1.1329 & 4.0 & 1.1356 & 4.2 & 0.9661 & -11.3 \\
\hline 10:0 & 1.0604 & 1.0980 & 3.6 & 1.0894 & 2.7 & 1.0872 & 2.5 & 1.1147 & 5.1 & 1.0908 & 2.9 \\
\hline 11:0 & 1.0366 & 1.1020 & 6.8 & 1.0595 & 2.7 & 1.0636 & 3.1 & 1.1000 & 6.1 & 1.0853 & 5.2 \\
\hline $5 c-11: 1$ & 1.0262 & 1.1220 & 9.4 & 1.1136 & 8.5 & 1.1108 & 8.2 & 1.1204 & 9.2 & 1.1095 & 8.1 \\
\hline 12:0 & 1.0168 & 1.0180 & 0.2 & 1.0444 & 2.7 & 1.0165 & 0.0 & 1.0570 & 3.9 & 1.0240 & 0.7 \\
\hline $9 c-12: 1$ & 1.0072 & 1.0620 & 5.5 & 1.0443 & 3.7 & 1.0432 & 3.6 & 1.0707 & 6.3 & 1.0433 & 3.6 \\
\hline 13:0 & 1.0000 & 1.0000 & 0.0 & 1.0000 & 0.0 & 1.0000 & 0.0 & 1.0000 & 0.0 & 1.0000 & 0.0 \\
\hline $12 c-13: 1$ & 0.9912 & 1.0635 & 7.3 & 1.0205 & 3.0 & 1.0425 & 5.2 & 1.0601 & 6.9 & 1.0339 & 4.3 \\
\hline 14:0 & 0.9856 & 0.9925 & 0.7 & 0.9971 & 1.2 & 0.9814 & -0.4 & 1.0144 & 2.9 & 0.9915 & 0.6 \\
\hline $9 c-14: 1$ & 0.9774 & 1.0177 & 4.2 & 1.0046 & 2.8 & 1.0130 & 3.6 & 1.0230 & 4.7 & 1.0097 & 3.3 \\
\hline 15:0 & 0.9731 & 0.9982 & 2.6 & 0.9675 & -0.6 & 0.9881 & 1.5 & 0.9713 & -0.2 & 0.9783 & 0.5 \\
\hline $10 c-15: 1$ & 0.9655 & 1.0148 & 5.1 & 0.9778 & 1.3 & 1.0290 & 6.6 & 0.9918 & 2.7 & 1.0037 & 4.0 \\
\hline 16:0 & 0.9622 & 0.9654 & 0.4 & 0.9545 & -0.8 & 0.9667 & 0.5 & 0.9685 & 0.7 & 0.9580 & -0.4 \\
\hline $9 t-16: 1$ & 0.9550 & 0.9725 & 1.9 & 0.9547 & 0.0 & 1.0072 & 5.5 & 0.9704 & 1.6 & 0.9587 & 0.4 \\
\hline $9 c-16: 1$ & 0.9550 & 0.9795 & 2.6 & 0.9604 & 0.6 & 0.9667 & 1.2 & 0.9713 & 1.7 & 0.9768 & 2.3 \\
\hline $17: 0$ & 0.9526 & 0.9868 & 3.6 & 0.9462 & -0.7 & 0.9743 & 2.3 & 0.9849 & 1.0 & 0.9558 & 0.3 \\
\hline $10 c-17: 1$ & 0.9458 & 0.9852 & 4.2 & 0.9568 & 1.2 & 0.9922 & 4.9 & 1.0030 & 6.0 & 0.9767 & 3.3 \\
\hline 18:0 & 0.9440 & 0.9621 & 1.9 & 0.9067 & -3.9 & 0.9526 & 0.9 & 0.9546 & 1.1 & 0.9390 & -0.5 \\
\hline $9 t-18: 1$ & 0.9377 & 1.0040 & 7.1 & 0.9441 & 0.7 & 0.9812 & 4.6 & 1.0394 & 10.8 & 0.9669 & 3.1 \\
\hline $11 t-18: 1$ & 0.9377 & 0.9847 & 5.0 & 0.9360 & -0.2 & 0.9735 & 3.8 & 0.9557 & 1.9 & 0.9364 & -0.1 \\
\hline $6 c-18: 1$ & 0.9377 & 0.9921 & 5.8 & 0.9949 & 6.1 & 0.9990 & 6.5 & 1.0229 & 9.1 & 0.9544 & 1.8 \\
\hline $9 c-18: 1$ & 0.9377 & 0.9377 & 0.0 & 0.9497 & 1.3 & 0.9419 & 0.4 & 0.9708 & 1.0 & 0.9359 & -0.2 \\
\hline $11 c-18: 1$ & 0.9377 & 0.9632 & 2.8 & 0.9366 & -0.1 & 0.9757 & 4.0 & 0.9609 & 1.0 & 0.9384 & 0.1 \\
\hline $9 t, 12 t-18: 2$ & 0.9313 & 0.9983 & 7.2 & 0.9375 & 0.7 & 0.9969 & 7.0 & 1.037 & 11.6 & 0.9756 & 4.8 \\
\hline $9 c, 12 c-18: 2$ & 0.9313 & 0.9400 & 1.0 & 0.9372 & 0.6 & 0.9459 & 1.6 & 0.9880 & 6.1 & 0.9390 & 0.8 \\
\hline $6 c, 9 c, 12 c-18: 3$ & 0.9249 & 1.0419 & 12.7 & 0.9458 & 2.3 & 0.9576 & 3.5 & 0.9919 & 6.5 & 0.9302 & 0.6 \\
\hline $9 c, 12 c, 15 c-18: 3$ & 0.9249 & 0.9259 & 0.1 & 0.9547 & 3.2 & 0.9410 & 1.7 & 0.9879 & 6.8 & 0.9405 & 0.2 \\
\hline 19:0 & 0.9364 & 0.9895 & 5.7 & 0.9074 & -3.1 & 0.8798 & -6.0 & 0.9921 & 5.9 & 0.9079 & -3.0 \\
\hline $7 c-19: 1$ & 0.9303 & 0.9338 & 0.4 & 0.9171 & -1.4 & 0.9449 & 1.6 & 1.0012 & 7.6 & 0.9390 & 0.8 \\
\hline 20:0 & 0.9295 & 0.9712 & 4.5 & 0.9164 & -1.4 & 0.9186 & -1.2 & 0.9953 & 1.1 & 0.9400 & 0.6 \\
\hline $5 c-20: 1$ & 0.9237 & 0.9777 & 5.9 & 0.9535 & 3.2 & 0.9350 & 1.2 & 1.0251 & 10.9 & 0.9312 & 0.2 \\
\hline $8 c-20: 1$ & 0.9237 & 0.9960 & 7.9 & 0.8841 & -4.3 & 0.9019 & -2.3 & 1.0201 & 10.4 & 0.9258 & 0.8 \\
\hline $11 c-20: 1$ & 0.9237 & 0.9724 & 5.3 & 0.9271 & 0.4 & 0.9154 & -0.9 & 1.0209 & 10.5 & 0.9273 & 1.7 \\
\hline $11 c, 14 c-20: 2$ & 0.9180 & 0.9612 & 4.7 & 0.9250 & 0.8 & 0.9268 & 1.0 & 1.0080 & 9.8 & 0.9241 & 0.4 \\
\hline $8 c, 11 c, 14 c-20: 3$ & - & 0.9278 & - & 0.9166 & - & 0.9409 & - & 1.0141 & - & 0.9272 & - \\
\hline $11 c, 14 c, 17 c-20: 3$ & - & 0.9466 & - & 0.9269 & & 0.9247 & & 1.0120 & & 0.9336 & \\
\hline $5 c, 8 c, 11 c, 14 c-20: 4$ & - & 0.8855 & - & 0.9467 & - & 0.8793 & - & 0.9754 & & 0.9034 & - \\
\hline $5 c, 8 c, 11 c, 14 c, 17 c-20: 5$ & - & 0.9371 & - & 0.9364 & - & 0.9478 & - & 1.0474 & - & 0.8891 & - \\
\hline 22:0 & 0.9176 & 1.0016 & 9.8 & 0.8893 & -2.5 & 0.8941 & -0.2 & 0.9663 & 5.3 & 0.9096 & 1.6 \\
\hline $13 c-22: 1$ & 0.9124 & 0.9459 & 4.3 & 0.9058 & -0.2 & 0.8995 & -0.9 & 1.0426 & 14.2 & 0.9022 & -0.3 \\
\hline $13 c, 16 c-22: 2$ & 0.9071 & 0.9624 & 6.1 & 0.8832 & -2.7 & 0.8980 & -1.0 & 1.0472 & 16.1 & 0.9238 & 2.8 \\
\hline
\end{tabular}


TABLE 1 (Continued $)$

\begin{tabular}{|c|c|c|c|c|c|c|c|c|c|c|c|}
\hline \multirow[b]{2}{*}{ FAME } & \multirow[b]{2}{*}{ TCFr } & \multicolumn{2}{|c|}{ Lab 1} & \multicolumn{2}{|c|}{ Lab 2} & \multicolumn{2}{|c|}{ Lab 3} & \multicolumn{2}{|c|}{ Lab 4} & \multicolumn{2}{|c|}{ Lab 5} \\
\hline & & ECF & $\Delta(\%)$ & ECF & $\Delta(\%)$ & ECF & $\Delta(\%)$ & ECF & $\Delta(\%)$ & ECF & $\Delta(\%)$ \\
\hline $13 c, 16 c, 19 c-22: 3$ & 0.9019 & 0.9503 & 5.4 & 0.9025 & 0.1 & 0.9213 & 2.0 & 1.0787 & 19.6 & 0.9472 & 6.1 \\
\hline $7 c, 10 c, 13 c, 16 c-22: 4$ & 0.8967 & 0.9112 & 1.7 & 0.9255 & 3.2 & 0.9270 & 3.3 & 1.0510 & 17.2 & 0.9211 & 0.5 \\
\hline $7 c, 10 c, 13 \mathrm{c}, 16 c, 19 c-22: 5$ & - & 0.9369 & - & 0.9361 & - & 0.9613 & - & 1.1128 & - & 0.9682 & - \\
\hline $4 c, 7 c, 10 c, 13 c, 16 c, 19 c-22: 6$ & - & 0.9448 & - & 0.9538 & - & 0.9855 & - & 1.1391 & - & 0.9954 & - \\
\hline 24:0 & 0.9076 & 0.9759 & 8.7 & 0.8900 & -0.9 & 0.8850 & -1.5 & 1.0579 & 16.5 & 0.9525 & -1.3 \\
\hline $15 c-24: 1$ & 0.9029 & 0.9073 & 1.6 & 0.8881 & -0.6 & 0.8930 & -0.1 & 1.0344 & 14.6 & 0.8977 & 5.0 \\
\hline
\end{tabular}

Abbreviations: TCFr, Theoretical correction factor; ECF, Empirical correction factor; $\Delta$, Difference between TCFr and ECF expressed as percentage. Values are the mean of triplicates.

FAMEs including, as appropriate, their positional and geometrical isomers. The mean \pm SD $(n=5)$ and recovery percentage for each certified FAME were calculated from the data presented by the five laboratories, reaching a final mean of 92.84 and $92.01 \mathrm{~g} \cdot 100 \mathrm{~g}^{-1}$ total FAME using ECF and TCFr with recovery percentages of $97.4 \%$ and $96.5 \%$, respectively (Table 2). The results for the seven certified FAMEs 14:0; 16:0; 16:1; 18:0; $18: 1 ; 18: 2$ and $18: 3$, were in agreement with the theoretical approach, because ECF and TCFr values for SFAs, MUFAs and PUFAs between 14 and 18 carbon atoms are close to one (Table 1). Therefore, either correction factor can be used to quantify these FAs in edible vegetable oils, as stated by Mosoba and Kramer (2009), and confirmed from the values calculated using both correction factors $(\mathrm{p}>0.05)$. Z score results were satisfactory according to Thompson et al. (2006). All the mean values for the seven certified FAMEs were $\leq 2 \mathrm{z}$, which confirms the homogenity of these results. Related to the non certified FAMEs, they corresponded to 23 FAMEs, between 10:0 to $13 c-22: 1$, in low percentages, between $0.05-0.9$ $\mathrm{g} \cdot 100 \mathrm{~g}^{-1}$ total FAME including some positional and geometric isomers.

\subsection{Fatty Acid composition of commercial fat samples}

The same modified temperature program indicated in 3.1 was applied in the GLC analysis of FAMEs from three commercial fat samples: a mixture of soybean and sunflower oil (80/20), fish oil and anhydrous butterfat. For the soybean/sunflower mixed oil, FAMEs were calculated by ECF and TCFr values, to compare both results according to the data discussed in 3.3. This procedure was not applied for fish oil or anhydrous butterfat (Mossoba and Kramer, 2009) for the reasons previously explained in 2.4 and 3.3. The FAMEs were calculated by the five laboratories, each laboratory using its own determined ECFs (Table 1). The final results corresponded to mean $\pm \mathrm{SD}(\mathrm{n}=5)$ of the data reported by each laboratory. To convert g FAME $100 \mathrm{~g}^{-1}$ FAME to $\mathrm{g}$ FA $100 \mathrm{~g}^{-1}$ FA and triacylglyceride equivalents $\%$ (TAGe) the respective Conversion Factors (CF) tabulated in the AOCS Method Ce 1j-07 (2007) were employed.

\subsubsection{Fatty acid composition of refined mixture of soybean and sunflower oil}

Eighteen FAs were identified and quantified in the soybean and sunflower oil mixture (80/20), seven SFAs, six MUFAs and five PUFAs, including

TABLE 2. Determined FAME content of the BCR 163 certified reference material and their respective recovery

\begin{tabular}{|c|c|c|c|c|c|}
\hline FATTY ACIDS & $\begin{array}{l}\text { Certified FAME content } \\
\quad\left(\mathrm{g} \cdot 100 \mathrm{~g}^{-1} \text { FAME }\right)\end{array}$ & $\begin{array}{l}\text { Determined FAME content } \\
\text { by ECF }\left(\mathrm{g} \cdot 100 \mathrm{~g}^{-1} \mathrm{FAME}\right)\end{array}$ & $\begin{array}{l}\text { Recovery } \\
\quad(\%)\end{array}$ & $\begin{array}{l}\text { Determined FAME content } \\
\text { by TCFr }\left(\mathrm{g} \cdot 100 \mathrm{~g}^{-1} \text { FAME }\right)\end{array}$ & $\begin{array}{l}\text { Recovery } \\
(\%)\end{array}$ \\
\hline 14:0\# & $2.29 \pm 0.04$ & $2.16 \pm 0.11$ & 94.3 & $2.16 \pm 0.07$ & 94.3 \\
\hline $16: 0 \#$ & $25.96 \pm 0.30$ & $25.28 \pm 0.65$ & 97.4 & $25.42 \pm 0.36$ & 97.9 \\
\hline $16: 1 \#$ & $2.58 \pm 0.16$ & $2.37 \pm 0.22$ & 91.9 & $2.26 \pm 0.22$ & 87.6 \\
\hline 18:0\# & $18.29 \pm 0.17$ & $17.80 \pm 0.66$ & 97.3 & $18.04 \pm 0.40$ & 98.6 \\
\hline $18: 1 \#$ & $38.30 \pm 0.40$ & $37.50 \pm 0.69$ & 97.9 & $36.52 \pm 2.53$ & 95.4 \\
\hline $18: 2 \#$ & $7.05 \pm 0.17$ & $6.95 \pm 0.13$ & 98.6 & $6.85 \pm 0.16$ & 97.2 \\
\hline $18: 3$ & $0.86 \pm 0.14$ & $0.78 \pm 0.07$ & 90.7 & $0.76 \pm 0.07$ & 88.4 \\
\hline Total & 95.33 & $92.84 \pm 1.90$ & 97.4 & $92.01 \pm 1.96$ & 96.5 \\
\hline
\end{tabular}

Mean value $\pm \mathrm{SD}(\mathrm{n}=5)$. For abbreviations see Table 1.

\# Includes, as appropriate, positional and geometrical (i.e. cis/trans ) isomers. 
cis-trans isomers (Table 3). The FAMEs resolution was good among the eighteen FAMEs, including the close polarity between 18:3 n-3 and $11 c-20: 1$ and the different amount found between both, confirming the high efficiency of the SP-2560 or CP Sil 88 columns and the good resolution obtained with the modified temperature program. FAs and TAGe values are within the literature range (Firestone, 2006). The content of $\alpha$-linolenic acid (mean value: $4.7 \mathrm{~g} \%$ ) was low compared with genuine soybean oil at around 7\% (Firestone, 2006), confirming the mix with sunflower oil (80:20), commercialized in Argentina, Chile, and declared in the ingredients.

PUFA was the predominant group $(60 \%)$, with linoleic acid being the main FA with a mean value of $54 \%$. MUFAs were $24 \%$, with oleic acid being the major constituent with $21 \%$. SFAs represented $15 \%$ and the main one was palmitic acid, reaching $11 \%$. The total $\mathrm{g}$ FAME $100 \mathrm{~g}^{-1}$ FAME using ECF or TCFr was up to $99 \%$ in both cases, and the conversion to $\mathrm{g} \cdot 100 \mathrm{~g}^{-1} \mathrm{FA}$ and TAGe gave values of $95 \%$ and $99.9 \%$, respectively, which were considered satisfactory. Thus, calculated ECF or tabulated TCFr can be used for quantitative purposes in this case. Chromatograms of the FAME separation and emerging time in two zones of the total FAMEs identified and quantified in this mixture of vegetable oils are presented in Figure 2A: zone $9 c-18: 1$ to $9 c, 12 c-18: 2$ and Figure 2B: zone 20:0-24:0.

Ratnayake et al., (2006) evaluated the same two polar columns for determining cis-, trans-FAs, SFAs, MUFAs and PUFAs in vegetable and not ruminant animal oils and fats using the AOCS Method Ce 1h-05 (2005), where the FA 21:0 as IS was used. In the present study, 13:0-TAG proposed by the AOCS Method Ce 1j-07 (2007) was utilized. According to previous experience, 21:0 elutes in the CLA isomers region interfere with the identification and quantification of these isomers that are present in milk fat and in deodorized fish oils. As these types of samples were

TABLE 3. Fatty acid composition of refined mixture of soybean and sunflower oil

\begin{tabular}{|c|c|c|c|c|c|c|c|c|}
\hline FATTY ACIDS & $\begin{array}{l}\text { FAME }_{\mathrm{ECF}} \\
\text { (g FAME·100 } \mathrm{g}^{-1} \\
\text { FAME) }\end{array}$ & $\begin{array}{c}\text { FA }_{\text {ECF }} \\
\left(\mathrm{gFA}^{-100 \mathrm{~g}^{-1}} \mathrm{FA}\right)\end{array}$ & $\begin{array}{c}\text { TAGe }_{\text {ECF }} \\
(\%)\end{array}$ & $\begin{array}{l}\text { FAME }_{\mathrm{TCFr}} \\
\text { (g FAME:100 } \mathrm{g}^{-1} \\
\text { FAME) }\end{array}$ & $\begin{array}{c}\mathbf{F A}_{\mathrm{TCFr}} \\
(\mathrm{g} \text { FA·100g } \\
\end{array}$ & $\begin{array}{c}\text { TAGe }_{\text {TCFr }} \\
(\%)\end{array}$ & ${ }^{*} \mathbf{F} \mathbf{A}_{\mathrm{CF}}$ & ${ }^{*} \mathrm{TAG}_{\mathrm{CF}}$ \\
\hline 14:0 & $0.09 \pm 0.02$ & $0.09 \pm 0.02$ & 0.09 & $0.09 \pm 0.02$ & $0.09 \pm 0.02$ & 0.09 & 0.9421 & 0.9945 \\
\hline 16:0 & $10.50 \pm 0.17$ & $9.96 \pm 0.15$ & 10.45 & $10.51 \pm 0.19$ & $9.96 \pm 0.18$ & 10.46 & 0.9481 & 0.9950 \\
\hline 17:0 & $0.10 \pm 0.02$ & $0.09 \pm 0.01$ & 0.10 & $0.10 \pm 0.01$ & $0.09 \pm 0.01$ & 0.10 & 0.9507 & 0.9953 \\
\hline 18:0 & $4.43 \pm 0.19$ & $4.23 \pm 0.18$ & 4.41 & $4.49 \pm 0.19$ & $4.28 \pm 0.16$ & 4.47 & 0.9530 & 0.9955 \\
\hline 20:0 & $0.15 \pm 0.05$ & $0.14 \pm 0.04$ & 0.15 & $0.15 \pm 0.05$ & $0.14 \pm 0.05$ & 0.15 & 0.9570 & 0.9959 \\
\hline $22: 0$ & $0.41 \pm 0.04$ & $0.39 \pm 0.04$ & 0.41 & $0.41 \pm 0.03$ & $0.39 \pm 0.03$ & 0.41 & 0.9604 & 0.9962 \\
\hline 24:0 & $0.15 \pm 0.03$ & $0.14 \pm 0.03$ & 0.15 & $0.15 \pm 0.03$ & $0.14 \pm 0.03$ & 0.15 & 0.9633 & 0.9965 \\
\hline ETotal SFA & 15.83 & 15.04 & 15.76 & 15.90 & 15.09 & 15.83 & & \\
\hline $9 c-16: 1$ & $0.09 \pm 0.01$ & $0.08 \pm 0.02$ & 0.09 & $0.08 \pm 0.02$ & $0.08 \pm 0.01$ & 0.08 & 0.9477 & 0.9950 \\
\hline $9 c-18: 1$ & $21.63 \pm 0.41$ & $20.61 \pm 0.42$ & 21.53 & $21.54 \pm 0.44$ & $20.52 \pm 0.45$ & 21.44 & 0.9477 & 0.9950 \\
\hline $11 c-18: 1$ & $1.27 \pm 0.04$ & $1.21 \pm 0.03$ & 1.26 & $1.25 \pm 0.05$ & $1.19 \pm 0.05$ & 1.24 & 0.9527 & 0.9955 \\
\hline $5 c-20: 1$ & $0.83 \pm 0.12$ & $0.79 \pm 0.13$ & 0.83 & $0.77 \pm 0.05$ & $0.74 \pm 0.05$ & 0.77 & 0.9568 & 0.9959 \\
\hline $8 c-20: 1$ & $0.68 \pm 0.06$ & $0.65 \pm 0.05$ & 0.68 & $0.66 \pm 0.06$ & $0.63 \pm 0.06$ & 0.66 & 0.9568 & 0.9959 \\
\hline $11 c-20: 1$ & $0.15 \pm 0.02$ & $0.14 \pm 0.03$ & 0.15 & $0.14 \pm 0.01$ & $0.14 \pm 0.01$ & 0.14 & 0.9568 & 0.9959 \\
\hline ¿Total MUFA & 24.65 & 23.48 & 24.54 & 24.44 & 23.30 & 24.33 & & \\
\hline $9 c, 12 t-18: 2$ & $0.55 \pm 0.03$ & $0.52 \pm 0.05$ & 0.55 & $0.54 \pm 0.03$ & $0.51 \pm 0.03$ & 0.54 & 0.9524 & 0.9954 \\
\hline $9 t, 12 c-18: 2$ & $0.55 \pm 0.06$ & $0.52 \pm 0.04$ & 0.55 & $0.54 \pm 0.07$ & $0.51 \pm 0.07$ & 0.54 & 0.9524 & 0.9954 \\
\hline $9 c, 12 c-18: 2$ & $53.93 \pm 0.57$ & $51.36 \pm 0.84$ & 53.68 & $53.56 \pm 0.65$ & $51.01 \pm 0.63$ & 53.31 & 0.9524 & 0.9954 \\
\hline $6 c, 9 c, 12 c-18: 3$ & $0.11 \pm 0.01$ & $0.10 \pm 0.01$ & 0.11 & $0.10 \pm 0.02$ & $0.10 \pm 0.01$ & 0.10 & 0.9520 & 0.9954 \\
\hline $9 c, 12 c, 15 c-18: 3$ & $4.76 \pm 0.29$ & $4.53 \pm 0.27$ & 4.74 & $4.69 \pm 0.22$ & $4.46 \pm 0.21$ & 4.67 & 0.9520 & 0.9954 \\
\hline ¿PUFAs cis, cis & 58.80 & 55.99 & 58.53 & 58.35 & 55.57 & 58.08 & & \\
\hline ¿PUFAs cis,trans & 1.10 & 1.04 & 1.10 & 1.08 & 1.02 & 1.08 & & \\
\hline ¿Total PUFAs & 59.90 & 57.03 & 59.63 & 59.43 & 56.59 & 59.16 & & \\
\hline ¿Total trans FAs & 1.10 & 1.04 & 1.10 & 1.08 & 1.02 & 1.08 & & \\
\hline ¿Total FAs & 100.38 & 95.55 & 99.93 & 99.77 & 94.98 & 99.32 & & \\
\hline
\end{tabular}

Mean value $\pm \operatorname{SD}(n=5)$. TAGe, Triacylglycerol equivalents; CF, Conversion factor. For other abbreviations see Table 1. 

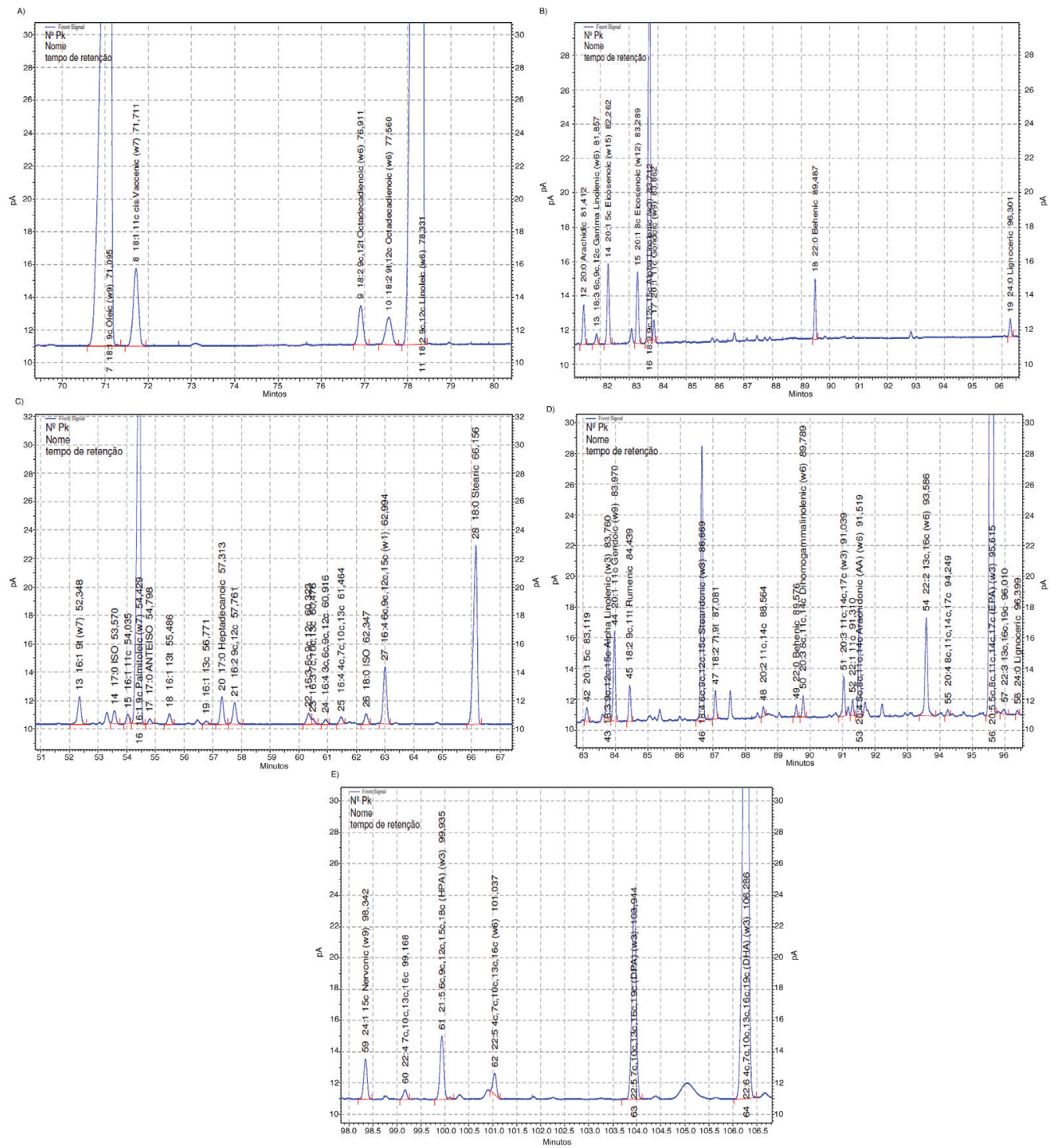

FIgURE 2. A. Significant part of the chromatogram of mixed soybean oil/Sunflower oil (80/20) showing the zone of FAMEs $9 c-18: 1$ to $9 c, 12 c-18: 2$ using the proposed temperature program.

B. Significant part of the chromatogram of mixed soybean oil/sunflower oil (80/20) showing the zone of FAMEs 20:0 to 24:0 using the proposed temperature program.

C. Significant part of the chromatogram of fish oil capsules showing the zone of FAMEs $9 t-16: 1$ to $18: 0$ using the proposed temperature program.

D. Significant part of the chromatogram of fish oil capsules showing the zone of FAMEs $5 c-20: 1$ to $24: 0$ using the proposed temperature program.

E. Significant part of the chromatogram of fish oil capsules showing the zone of FAMEs 24:1 to $4 c, 7 c, 10 c, 13 c, 16 c, 19 c-22: 6$, DHA using the proposed temperature program.

also analyzed in the present study, the use of 13:0-TAG was justified. The absence of 13:0 was checked in the samples analyzed. It is the best internal standard for butterfat according to Mossoba and Kramer (2009). AOCS Official Methods Ce 2b-11 (2011) and Ce 2c-11 (2011) indicate that in addition to 13:0-TAG, 21:0TAG and 23:0-TAG as IS can be used for vegetable and fish oils, respectively.

\subsubsection{Fatty acid composition of fish oil}

In total, sixty three FAMEs were identified and quantified in the fish oil sample (Table 4). They were separated by groups: seventeen SFAs, eighteen MUFAs and twenty eight PUFAs. Fish oil FAs are complex to separate and to identify, considering their different polarity related to chain length, 
10 - L. Masson, T. Alfaro, C. Camilo, A. Carvalho, P. Illesca, R. Torres, M. Tavares do Carmo, J. Mancini-Filho and C. Bernal

TABLE 4. Fatty acid composition of fish oil

\begin{tabular}{|c|c|c|c|c|c|}
\hline FATTY ACIDS & $\begin{array}{c}\text { FAME }_{\text {ECF }} \\
\left(\text { gFAME}^{\prime} 100 \mathrm{~g}^{-1} \text { FAME) }\right.\end{array}$ & $\begin{array}{c}\mathrm{FA}_{\mathrm{ECF}} \\
\left(\mathrm{g} \mathrm{FA} \cdot 100 \mathrm{~g}^{-1} \mathrm{FA}\right)\end{array}$ & $\begin{array}{c}\text { TAGe }_{\text {ECF }} \\
(\%)\end{array}$ & ${ }^{*} \mathbf{F} \mathbf{A}_{\mathrm{CF}}$ & ${ }^{*} \mathbf{T A G}_{\mathrm{CF}}$ \\
\hline $12: 0$ & $0.11 \pm 0.02$ & $0.10 \pm 0.01$ & 0.11 & 0.9346 & 0.9937 \\
\hline Iso-13:0 & $0.02 \pm 0.01$ & $0.02 \pm 0.01$ & 0.02 & 0.9386 & 0.9941 \\
\hline Iso-14:0 & $0.05 \pm 0.01$ & $0.05 \pm 0.01$ & 0.05 & 0.9421 & 0.9945 \\
\hline $14: 0$ & $7.35 \pm 0.43$ & $6.92 \pm 0.45$ & 7.31 & 0.9421 & 0.9945 \\
\hline Iso-15:0 & $0.22 \pm 0.02$ & $0.21 \pm 0.02$ & 0.22 & 0.9453 & 0.9948 \\
\hline AnteIso-15:0 & $0.06 \pm 0.01$ & $0.06 \pm 0.01$ & 0.06 & 0.9453 & 0.9948 \\
\hline $15: 0$ & $0.52 \pm 0.02$ & $0.49 \pm 0.03$ & 0.52 & 0.9453 & 0.9948 \\
\hline Iso-16:0 & $0.08 \pm 0.01$ & $0.07 \pm 0.01$ & 0.08 & 0.9481 & 0.9950 \\
\hline $16: 0$ & $16.18 \pm 1.10$ & $15.34 \pm 0.86$ & 16.10 & 0.9481 & 0.9950 \\
\hline ISo-17:0 & $0.20 \pm 0.03$ & $0.19 \pm 0.03$ & 0.20 & 0.9507 & 0.9953 \\
\hline AnteIso-17:0 & $0.08 \pm 0.03$ & $0.08 \pm 0.03$ & 0.08 & 0.9507 & 0.9953 \\
\hline $17: 0$ & $0.43 \pm 0.01$ & $0.41 \pm 0.01$ & 0.43 & 0.9507 & 0.9953 \\
\hline Iso-18:0 & $0.14 \pm 0.03$ & $0.13 \pm 0.02$ & 0.14 & 0.9530 & 0.9955 \\
\hline 18:0 & $3.21 \pm 0.27$ & $3.06 \pm 0.19$ & 3.20 & 0.9530 & 0.9955 \\
\hline 20:0 & $0.19 \pm 0.03$ & $0.18 \pm 0.03$ & 0.19 & 0.9570 & 0.9959 \\
\hline 22:0 & $0.16 \pm 0.05$ & $0.15 \pm 0.04$ & 0.16 & 0.9602 & 0.9962 \\
\hline 24:0 & $0.03 \pm 0.02$ & $0.03 \pm 0.02$ & 0.03 & 0.9630 & 0.9965 \\
\hline ETotal SFA & 29.03 & 27.49 & 28.90 & & \\
\hline $9 c-14: 1$ & $0.06 \pm 0.03$ & $0.06 \pm 0.03$ & 0.06 & 0.9417 & 0.9944 \\
\hline $10 c-15: 1$ & $0.04 \pm 0.01$ & $0.03 \pm 0.02$ & 0.04 & 0.9449 & 0.9947 \\
\hline $9 t-16: 1$ & $0.43 \pm 0.03$ & $0.41 \pm 0.04$ & 0.43 & 0.9477 & 0.9950 \\
\hline $11 c-16: 1$ & $0.12 \pm 0.02$ & $0.12 \pm 0.02$ & 0.12 & 0.9704 & 0.9950 \\
\hline $9 c-16: 1$ & $8.39 \pm 0.43$ & $8.14 \pm 0.42$ & 8.35 & 0.9704 & 0.9950 \\
\hline $13 t-16: 1$ & $0.19 \pm 0.06$ & $0.18 \pm 0.05$ & 0.19 & 0.9704 & 0.9950 \\
\hline $13 c-16: 1$ & $0.07 \pm 0.02$ & $0.07 \pm 0.02$ & 0.07 & 0.9704 & 0.9950 \\
\hline $6 t+8 t-18: 1$ & $1.10 \pm 0.09$ & $1.07 \pm 0.12$ & 1.10 & 0.9704 & 0.9955 \\
\hline $9 t-18: 1$ & $0.06 \pm 0.02$ & $0.06 \pm 0.01$ & 0.06 & 0.9704 & 0.9955 \\
\hline $10 t-18: 1$ & $0.06 \pm 0.01$ & $0.06 \pm 0.01$ & 0.06 & 0.9704 & 0.9955 \\
\hline $9 c-18: 1$ & $9.67 \pm 0.59$ & $9.38 \pm 0.40$ & 9.63 & 0.9704 & 0.9955 \\
\hline $11 c-18: 1$ & $3.10 \pm 0.23$ & $3.01 \pm 0.16$ & 3.09 & 0.9704 & 0.9955 \\
\hline $13 c-18: 1$ & $0.09 \pm 0.02$ & $0.08 \pm 0.02$ & 0.09 & 0.9704 & 0.9955 \\
\hline $14 c-18: 1$ & $0.10 \pm 0.03$ & $0.09 \pm 0.03$ & 0.10 & 0.9704 & 0.9955 \\
\hline $5 c-20: 1$ & $0.14 \pm 0.03$ & $0.13 \pm 0.02$ & 0.14 & 0.9520 & 0.9959 \\
\hline $11 c-20: 1$ & $0.75 \pm 0.07$ & $0.72 \pm 0.06$ & 0.75 & 0.9568 & 0.9959 \\
\hline $11 c-22: 1$ & $0.13 \pm 0.02$ & $0.12 \pm 0.02$ & 0.13 & 0.9600 & 0.9962 \\
\hline $15 c-24: 1$ & $0.35 \pm 0.02$ & $0.34 \pm 0.02$ & 0.35 & 0.9628 & 0.9965 \\
\hline EMUFA cis & 23.01 & 22.29 & 22.92 & & \\
\hline EMUFA trans & 1.84 & 1.78 & 1.84 & & \\
\hline ¿Total MUFA & 24.85 & 24.07 & 24.76 & & \\
\hline $9 c, 12 c-16: 2$ & $0.29 \pm 0.06$ & $0.27 \pm 0.06$ & 0.29 & 0.9473 & 0.9950 \\
\hline $6 c, 9 c, 12 c-16: 3$ & $0.19 \pm 0.03$ & $0.18 \pm 0.03$ & 0.19 & 0.9469 & 0,9950 \\
\hline $7 c, 10 c, 13 c-16: 3$ & $0.08 \pm 0.01$ & $0.08 \pm 0.01$ & 0.08 & 0.9469 & 0.9950 \\
\hline $3 c, 6 c, 9 c, 12 c-16: 4$ & $0.08 \pm 0.02$ & $0.08 \pm 0.02$ & 0.08 & 0.9465 & 0.9950 \\
\hline $4 c, 7 c, 10 c, 13 c-16: 4$ & $0.13 \pm 0.03$ & $0.12 \pm 0.03$ & 0.13 & 0.9465 & 0.9950 \\
\hline $6 c, 9 c, 12 c, 15 c-16: 4$ & $1.04 \pm 0.13$ & $0.98 \pm 0.14$ & 1.03 & 0.9465 & 0.9950 \\
\hline $9 t, 12 t-18: 2$ & $0.08 \pm 0.01$ & $0.08 \pm 0.02$ & 0.08 & 0.9524 & 0.9954 \\
\hline
\end{tabular}


TABLE 4 (Continued $)$

\begin{tabular}{|c|c|c|c|c|c|}
\hline FATTY ACIDS & 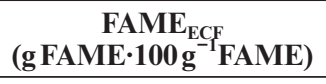 & $\begin{array}{c}\text { FA }_{\mathrm{ECF}} \\
\left(\mathrm{g} \mathrm{FA} \cdot 100 \mathrm{~g}^{-1} \mathrm{FA}\right) \\
\end{array}$ & $\begin{array}{c}\text { TAGe }_{\text {ECF }} \\
(\%) \\
\end{array}$ & ${ }^{*} \mathbf{F} A_{\mathrm{CF}}$ & ${ }^{*} \mathbf{T A G}_{\mathrm{CF}}$ \\
\hline $8 c, 11 c-18: 2$ & $0.15 \pm 0.04$ & $0.14 \pm 0.04$ & 0.15 & 0.9524 & 0.9954 \\
\hline $9 c, 12 c-18: 2$ & $2.04 \pm 0.12$ & $1.94 \pm 0.14$ & 2.03 & 0.9524 & 0.9954 \\
\hline $11 c, 14 c-18: 2$ & $0.36 \pm 0.05$ & $0.34 \pm 0.05$ & 0.36 & 0.9524 & 0.9954 \\
\hline $9 c, 11 t-18: 2$ & $0.28 \pm 0.03$ & $0.27 \pm 0.03$ & 0.28 & 0.9524 & 0.9954 \\
\hline $7 t, 9 t-18: 2$ & $0.24 \pm 0.03$ & $0.23 \pm 0.03$ & 0.24 & 0.9524 & 0.9954 \\
\hline $6 c, 9 c, 12 c-18: 3$ & $0.20 \pm 0.02$ & $0.19 \pm 0.03$ & 0.20 & 0.9520 & 0.9954 \\
\hline $9 c, 12 c, 15 c-18: 3$ & $0.71 \pm 0.08$ & $0.68 \pm 0.07$ & 0.71 & 0.9520 & 0.9954 \\
\hline $6 c, 9 c, 12 c, 15 c-18: 4$ & $2.34 \pm 0.34$ & $2.23 \pm 0.36$ & 2.33 & 0.9517 & 0.9954 \\
\hline $11 c, 14 c-20: 2$ & $0.17 \pm 0.03$ & $0.16 \pm 0.03$ & 0.17 & 0.9565 & 0.9958 \\
\hline $8 c, 11 c, 14 c-20: 3$ & $0.11 \pm 0.03$ & $0.11 \pm 0.03$ & 0.11 & 0.9562 & 0.9958 \\
\hline $11 c, 14 c, 17 c-20: 3$ & $0.32 \pm 0.01$ & $0.31 \pm 0.02$ & 0.32 & 0.9562 & 0.9958 \\
\hline $5 c, 8 c, 11 c, 14 c-20: 4$ & $0.84 \pm 0.06$ & $0.80 \pm 0.07$ & 0.84 & 0.9560 & 0.9958 \\
\hline $8 c, 11 c, 14 c, 17 c-20: 4$ & $0.05 \pm 0.01$ & $0.04 \pm 0.01$ & 0.05 & 0.9560 & 0.9958 \\
\hline $5 c, 8 c, 11 c, 14 c, 17 c-20: 5$ & $16.85 \pm 0.99$ & $16.10 \pm 0.87$ & 16.78 & 0.9557 & 0.9958 \\
\hline $4 c, 7 c, 10 c, 13 c, 16 c-21: 5$ & $0.62 \pm 0.07$ & $0.59 \pm 0.08$ & 0.62 & 0.9578 & 0.9961 \\
\hline $13 c, 16 c-22: 2$ & $0.80 \pm 0.12$ & $0.77 \pm 0.12$ & 0.80 & 0.9600 & 0.9962 \\
\hline $13 c, 16 c, 19 c-22: 3$ & $0.04 \pm 0.01$ & $0.04 \pm 0.02$ & 0.04 & 0.9598 & 0.9961 \\
\hline $7 c, 10 c, 13 c, 16 c-22: 4$ & $0.09 \pm 0.01$ & $0.09 \pm 0.02$ & 0.09 & 0.9595 & 0.9961 \\
\hline $4 c, 7 c, 10 c, 13 c, 16 c-22: 5$ & $0.31 \pm 0.06$ & $0.30 \pm 0.06$ & 0.31 & 0.9593 & 0.9961 \\
\hline $7 c, 10 c, 13 c, 16 c, 19 c-22: 5$ & $2.19 \pm 0.14$ & $2.10 \pm 0.14$ & 2.18 & 0.9593 & 0.9961 \\
\hline $4 c, 7 c, 10 c, 13 c, 16 c, 19 c-22: 6$ & $10.93 \pm 0.79$ & $10.48 \pm 0.75$ & 10.89 & 0.9590 & 0.9961 \\
\hline ¿PUFAs cis, cis & 40.93 & 39.12 & 40.78 & & \\
\hline EPUFAs cis,trans & 0.60 & 0.58 & 0.60 & & \\
\hline ¿Total PUFAs & 41.53 & 39.70 & 41.38 & & \\
\hline ¿Total trans FAs & 2.44 & 2.36 & 2.44 & & \\
\hline \multicolumn{6}{|l|}{ ¿Total FAs } \\
\hline & 95.41 & 91.26 & 95.04 & & \\
\hline
\end{tabular}

Mean value $\pm \operatorname{SD}(n=5)$. For abbreviations see Table 1 and 3.

double bonds from 2 to 6 and positional and geometric isomers with the same carbon number.

For the identification of FAMEs, different standards and literature data were consulted. The standard GLC 463 has 52 FAMEs, 34 of them being present in the fish oil analyzed (65\%). Santercole et al. 2012, using direct GLC and fractions obtained with silver ions, quantified the FAMEs in Menhaden oil (MO) and Sparus aurata fish oil using an SP-2560 $100 \mathrm{~m}$ capillary column. The temperature program takes $110.3 \mathrm{~min}$, practically the same time as the program developed in this work (110 min). GLC 463 for FAME identification was also used. A good agreement was found in the elution order and FAME identification between both studies, even though they employed different samples.

Chromatograms of the FAME in three zones of the total FAMEs identified and quantified in the fish oil sample analyzed are presented. Figure 2C shows $9 t-16: 1$ to $18: 0$, Figure 2D: $5 c-20: 1$ to 24,0 and Figure 2E: $15 c-24,1$ to 22,6 DHA. It is important to mention that the FAME elution and identification presented in Figure 2D and in Figure 2E follow practically the same order indicated for MO in Santercole el al., 2012, who concluded that better results were obtained using the SP-2560 capillary column than the Supercowax $-10,30 \mathrm{~m}$ indicated in the Official AOCS Method Ce 1i-07 (AOCS, 2007a) for marine oils. Some small peaks were not identified, their retention times not fitting available standards.

The PUFA group achieved the major percentage of the total FAs $(40 \%), 20: 5 n-3$ and $22: 6$ n-3 being the most abundant with $16.9 \%$ and $10.9 \%$, respectively. This FA composition agrees with data published for fish oils, where SFAs and MUFAs are in equivalent proportion and PUFAs are the prevalent group (SFAs: MUFAs: PUFAs/ 1.0: 0.9: 1.4) 
(Romero et al., 1996; Ackman, 1998; Firestone, 2006; Mendez et al., 2010). It is worth mentioning that the temperature program is key in the elution order of the FAMEs with close polarity and different structure; any small change in the temperature program used can produce overlapping between $9 c, 12 c, 15 c-18: 3$ with $11 c-20: 1 ; 11 c-22: 1$ with $20: 4$ n-6, 20:5 n-3 with $24: 0$ or changes in the elution order. The modified temperature program used made it possible to identify and properly quantify a total of sixty three FAMEs. The mean value obtained among the five laboratories of $95.41 \mathrm{~g} \mathrm{FAME} \cdot 100 \mathrm{~g}^{-1}$ of FAMEs is considered satisfactory, Table 4.

\subsubsection{Fatty acid composition of anhydrous butterfat}

Anhydrous butterfat is another complex animal fat to analyze FA composition by GLC due the large number of FAs with wide carbon chain numbers and different isomers, starting with butyric acid (4:0) as shown in Figure 3A. Numerous papers have been published in recent years related to butterfat FA analysis, with a special mention for the separation and identification of trans isomers. Differences in quantity and distribution of 18:1 trans-isomers formed in ruminant and industrial processing constitute an interesting health issue, as has been described by Mossoba and Kramer (2009). The $11 t$-18:1 trans- vaccenic acid is the most abundant FA isomer in ruminant fats, as can be observed in Figure 3B. The rumenic acid $(9 c, 11 t-18: 2)$, the main CLA isomer present in milk fat and very important FA due to its biological role (Roach et al., 2000; Dionisi et al., 2002; Kramer et al., 2004; Destaillats et al., 2007) is clearly identified in Figure 3C.

Each laboratory reported the mean value for each FAME identified, expressed as g FAME $100 \mathrm{~g}^{-1}$ FAMEs at a final mean value $\pm \operatorname{SD}(n=5)$ for each FAME and the results are presented in Table 5.

Seventy-three FAMEs were identified and quantified. They were organized by groups, SFAs, MUFAs and PUFAs, including their respective positional
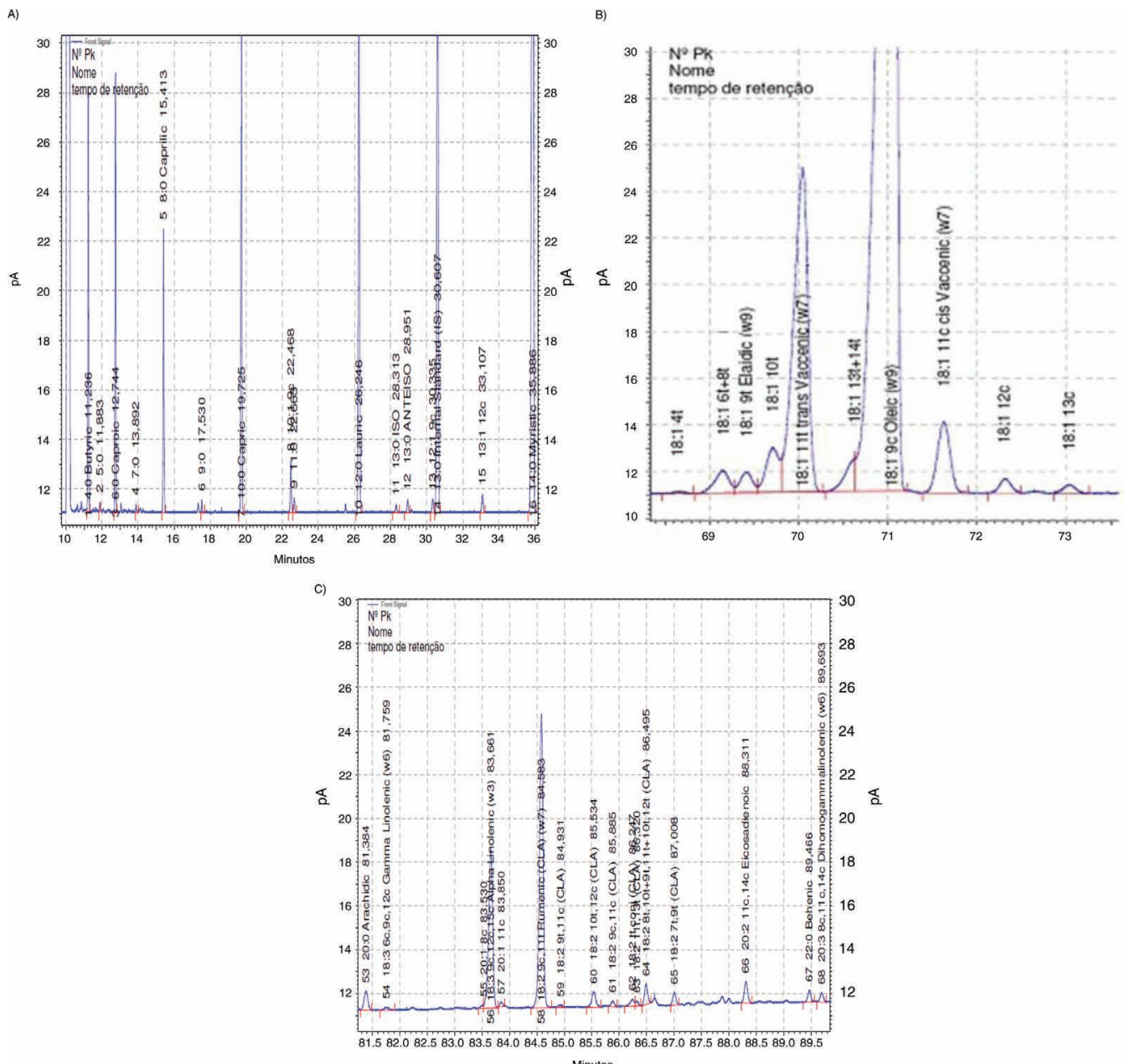

FIGURE 3. Significant parts of the chromatogram of anhydrous butterfat showing the zones of FAMEs: A. 4:0 to 14:0, B. $4 t-18: 1$ to $13 c-18: 1$ and C. $20: 0$ to $11 \mathrm{c}, 14 \mathrm{c}, 17 \mathrm{c}-20: 3$ using the proposed temperature program. 
Fatty acid composition of soybean/sunflower mix oil, fish oil and butterfat $\bullet 13$

TABLE 5. Fatty acid composition of anhydrous butterfat

\begin{tabular}{|c|c|c|c|c|c|}
\hline FATTY ACIDS & 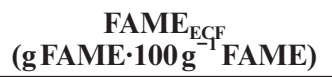 & $\begin{array}{c}\text { FA }_{\mathrm{ECF}} \\
\left(\mathrm{g} \mathrm{FA} \cdot 100 \mathrm{~g}^{-1} \mathrm{FA}\right)\end{array}$ & $\begin{array}{c}\text { TAGe }_{\mathrm{ECF}} \\
(\%)\end{array}$ & $\mathbf{F A}_{\mathbf{C F}}$ & $\mathbf{T A G}_{\mathrm{CF}}$ \\
\hline $4: 0$ & $2.33 \pm 0.73$ & $1.99 \pm 0.62$ & 2.30 & 0.8623 & 0.9868 \\
\hline $5: 0$ & $0.06 \pm 0.05$ & $0.05 \pm 0.05$ & 0.06 & 0.8792 & 0.9884 \\
\hline $6: 0$ & $1.89 \pm 0.31$ & $1.69 \pm 0.28$ & 1.87 & 0.8922 & 0.9897 \\
\hline $7: 0$ & $0.03 \pm 0.00$ & $0.03 \pm 0.00$ & 0.03 & 0.9027 & 0.9907 \\
\hline $8: 0$ & $1.24 \pm 0.11$ & $1.13 \pm 0.13$ & 1.23 & 0.9114 & 0.9915 \\
\hline 9:0 & $0.03 \pm 0.01$ & $0.03 \pm 0.01$ & 0.03 & 0.9186 & 0.9922 \\
\hline 10:0 & $2.81 \pm 0.27$ & $2.60 \pm 0.26$ & 2.79 & 0.9247 & 0.9928 \\
\hline 11:0 & $0.06 \pm 0.02$ & $0.06 \pm 0.01$ & 0.06 & 0.9296 & 0.9933 \\
\hline $12: 0$ & $3.34 \pm 0.43$ & $3.12 \pm 0.42$ & 3.32 & 0.9346 & 0.9937 \\
\hline Iso-13:0 & $0.05 \pm 0.01$ & $0.05 \pm 0.01$ & 0.05 & 0.9386 & 0.9941 \\
\hline Anteiso-13:0 & $0.07 \pm 0.01$ & $0.07 \pm 0.01$ & 0.07 & 0.9386 & 0.9941 \\
\hline $14: 0$ & $10.74 \pm 0.58$ & $10.12 \pm 0.68$ & 10.68 & 0.9421 & 0.9945 \\
\hline Anteiso-15:0 & $0.59 \pm 0.07$ & $0.56 \pm 0.07$ & 0.59 & 0.9453 & 0.9948 \\
\hline $15: 0$ & $1.18 \pm 0.14$ & $1.12 \pm 0.14$ & 1.17 & 0.9453 & 0.9948 \\
\hline Iso-16:0 & $0.26 \pm 0.03$ & $0.25 \pm 0.03$ & 0.26 & 0.9481 & 0.9950 \\
\hline $16: 0$ & $26.74 \pm 1.01$ & $25.35 \pm 1.05$ & 26.61 & 0.9481 & 0.9950 \\
\hline Iso-17:0 & $0.09 \pm 0.01$ & $0.08 \pm 0.02$ & 0.09 & 0.9507 & 0.9953 \\
\hline $17: 0$ & $0.62 \pm 0.06$ & $0.60 \pm 0.06$ & 0.62 & 0.9507 & 0.9953 \\
\hline 18:0 & $11.27 \pm 0.83$ & $10.74 \pm 0.73$ & 11.22 & 0.9530 & 0.9955 \\
\hline 19:0 & $0.08 \pm 0.03$ & $0.08 \pm 0.02$ & 0.08 & 0.9551 & 0.9957 \\
\hline $20: 0$ & $0.15 \pm 0.03$ & $0.14 \pm 0.03$ & 0.15 & 0.9570 & 0.9959 \\
\hline $22: 0$ & $0.07 \pm 0.02$ & $0.07 \pm 0.02$ & 0.07 & 0.9602 & 0.9962 \\
\hline $24: 0$ & $0.05 \pm 0.01$ & $0.04 \pm 0.01$ & 0.05 & 0.9630 & 0.9965 \\
\hline ¿Total SFA & 63.75 & 59.97 & 63.40 & & \\
\hline $9 c-10: 1$ & $0.24 \pm 0.05$ & $0.22 \pm 0.04$ & 0.24 & 0.9239 & 0.9927 \\
\hline $9 c-12: 1$ & $0.08 \pm 0.02$ & $0.08 \pm 0.02$ & 0.08 & 0.9339 & 0.9937 \\
\hline $12 c-13: 1$ & $0.12 \pm 0.02$ & $0.11 \pm 0.02$ & 0.12 & 0.938 & 0.9941 \\
\hline $9 t-14: 1$ & $0.36 \pm 0.16$ & $0.34 \pm 0.15$ & 0.36 & 0.9416 & 0.9944 \\
\hline $9 c-14: 1$ & $0.88 \pm 0.10$ & $0.83 \pm 0.09$ & 0.88 & 0.9416 & 0.9944 \\
\hline $9 t-16: 1$ & $0.13 \pm 0.03$ & $0.12 \pm 0.02$ & 0.13 & 0.9477 & 0.9950 \\
\hline $11 t-16: 1$ & $0.38 \pm 0.17$ & $0.36 \pm 0.16$ & 0.38 & 0.9477 & 0.9950 \\
\hline $9 c-16: 1$ & $1.26 \pm 0.24$ & $1.19 \pm 0.23$ & 1.25 & 0.9477 & 0.9950 \\
\hline $10 c-16: 1$ & $0.50 \pm 0.06$ & $0.47 \pm 0.22$ & 0.50 & 0.9477 & 0.9950 \\
\hline $11 c-16: 1$ & $0.16 \pm 0.04$ & $0.15 \pm 0.04$ & 0.16 & 0.9477 & 0.9950 \\
\hline $9 c-17: 1$ & $0.23 \pm 0.04$ & $0.22 \pm 0.04$ & 0.23 & 0.9503 & 0.9952 \\
\hline $4 t-18: 1$ & $0.04 \pm 0.01$ & $0.04 \pm 0.01$ & 0.04 & 0.9527 & 0.9955 \\
\hline $6 t-8 t-18: 1$ & $0.33 \pm 0.06$ & $0.31 \pm 0.06$ & 0.33 & 0.9527 & 0.9955 \\
\hline $9 t-18: 1$ & $0.26 \pm 0.02$ & $0.25 \pm 0.01$ & 0.26 & 0.9527 & 0.9955 \\
\hline $10 t-18: 1$ & $0.57 \pm 0.03$ & $0.54 \pm 0.04$ & 0.57 & 0.9527 & 0.9955 \\
\hline $11 t-18: 1$ & $2.39 \pm 0.12$ & $2.28 \pm 0.11$ & 2.38 & 0.9527 & 0.9955 \\
\hline $13 t-14 t-18: 1$ & $0.22 \pm 0.06$ & $0.21 \pm 0.06$ & 0.22 & 0.9527 & 0.9955 \\
\hline $9 c-18: 1$ & $21.80 \pm 0.98$ & $20.77 \pm 1.02$ & 21.70 & 0.9527 & 0.9955 \\
\hline $11 c-18: 1$ & $0.90 \pm 0.05$ & $0.86 \pm 0.04$ & 0.90 & 0.9527 & 0.9955 \\
\hline $12 c-18: 1$ & $0.27 \pm 0.02$ & $0.26 \pm 0.02$ & 0.27 & 0.9527 & 0.9955 \\
\hline $13 c-18: 1$ & $0.08 \pm 0.02$ & $0.08 \pm 0.02$ & 0.08 & 0.9527 & 0.9955 \\
\hline $14 c-18: 1$ & $0.06 \pm 0.00$ & $0.06 \pm 0.01$ & 0.06 & 0.9527 & 0.9955 \\
\hline
\end{tabular}

Grasas Aceites 66 (1), January-March 2015, e064. ISSN-L: 0017-3495 doi: http://dx.doi.org/10.3989/gya.0692141 
14 - L. Masson, T. Alfaro, C. Camilo, A. Carvalho, P. Illesca, R. Torres, M. Tavares do Carmo, J. Mancini-Filho and C. Bernal

TABLE 5 (Continued)

\begin{tabular}{|c|c|c|c|c|c|}
\hline FATTY ACIDS & 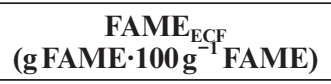 & $\begin{array}{c}\mathrm{FA}_{\mathrm{ECF}} \\
\left(\mathrm{g} \mathrm{FA} \cdot 100 \mathrm{~g}^{-1} \mathrm{FA}\right) \\
\end{array}$ & $\begin{array}{c}\text { TAGe }_{\text {ECF }} \\
(\%)\end{array}$ & $\mathbf{F A}_{\mathbf{C F}}$ & $\mathbf{T A G}_{\mathrm{CF}}$ \\
\hline $16 t-18: 1$ & $0.49 \pm 0.07$ & $0.47 \pm 0.07$ & 0.49 & 0.9527 & 0.9955 \\
\hline $15 c-18: 1$ & $0.18 \pm 0.07$ & $0.17 \pm 0.07$ & 0.18 & 0.9527 & 0.9955 \\
\hline $8 c-20: 1$ & $0.05 \pm 0.01$ & $0.05 \pm 0.01$ & 0.05 & 0.9568 & 0.9959 \\
\hline $11 c-20: 1$ & $0.01 \pm 0.01$ & $0.01 \pm 0.00$ & 0.01 & 0.9568 & 0.9959 \\
\hline $15 c-24: 1$ & $0.04 \pm 0.01$ & $0.03 \pm 0.01$ & 0.04 & 0.9628 & 0.9965 \\
\hline EMUFA cis & 26.86 & 25.56 & 26.75 & & \\
\hline EMUFA trans & 5.17 & 4.92 & 5.16 & & \\
\hline ¿Total MUFA & 32.03 & 30.48 & 31.91 & & \\
\hline $9 t, 12 t-18: 2$ & $0.11 \pm 0.01$ & $0.11 \pm 0.02$ & 0.11 & 0.9524 & 0.9954 \\
\hline $9 t, 13 c-18: 2+8 t, 12 c-18: 2$ & $0.15 \pm 0.01$ & $0.14 \pm 0.01$ & 0.15 & 0.9524 & 0.9954 \\
\hline $9 c, 12 t-18: 2+8 t, 13 c-18: 2$ & $0.05 \pm 0.03$ & $0.05 \pm 0.03$ & 0.05 & 0.9524 & 0.9954 \\
\hline $9 t, 12 c-18: 2$ & $0.52 \pm 0.31$ & $0.50 \pm 0.35$ & 0.52 & 0.9524 & 0.9954 \\
\hline $11 t, 15 c-18: 2$ & $0.08 \pm 0.02$ & $0.08 \pm 0.02$ & 0.08 & 0.9524 & 0.9954 \\
\hline $9 c, 12 c-18: 2$ & $2.11 \pm 0.20$ & $2.01 \pm 0.21$ & 2.10 & 0.9524 & 0.9954 \\
\hline $9 c, 15 c-18: 2$ & $0.08 \pm 0.02$ & $0.08 \pm 0.03$ & 0.08 & 0.9524 & 0.9954 \\
\hline $6 c, 9 c, 12 c-18: 3$ & $0.03 \pm 0.01$ & $0.03 \pm 0.01$ & 0.03 & 0.9520 & 0.9954 \\
\hline $9 c, 12 c, 15 c-18: 3$ & $0.75 \pm 0.22$ & $0.71 \pm 0.21$ & 0.75 & 0.9520 & 0.9954 \\
\hline $9 c, 11 t-18: 2$ & $1.19 \pm 0.43$ & $1.13 \pm 0.42$ & 1.18 & 0.9524 & 0.9954 \\
\hline $9 t, 11 c-18: 2$ & $0.02 \pm 0.00$ & $0.02 \pm 0.00$ & 0.02 & 0.9524 & 0.9954 \\
\hline $10 t, 12 c-18: 2$ & $0.05 \pm 0.03$ & $0.05 \pm 0.03$ & 0.05 & 0.9524 & 0.9954 \\
\hline $9 c, 11 c-18: 2$ & $0.03 \pm 0.01$ & $0.03 \pm 0.01$ & 0.03 & 0.9524 & 0.9954 \\
\hline $11 t, 13 t-18: 2$ & $0.03 \pm 0.01$ & $0.03 \pm 0.01$ & 0.03 & 0.9524 & 0.9954 \\
\hline $\begin{array}{l}8 t, 10 t+9 t, 11 t+ \\
10 t, 12 t-18: 2\end{array}$ & $0.08 \pm 0.01$ & $0.08 \pm 0.01$ & 0.08 & 0.9524 & 0.9954 \\
\hline $7 t, 9 t-18: 2$ & $0.03 \pm 0.02$ & $0.03 \pm 0.02$ & 0.03 & 0.9524 & 0.9954 \\
\hline $11 c, 14 c-20: 2$ & $0.10 \pm 0.02$ & $0.09 \pm 0.02$ & 0.10 & 0.9565 & 0.9958 \\
\hline $8 c, 11 c, 14 c-20: 3$ & $0.07 \pm 0.02$ & $0.06 \pm 0.02$ & 0.07 & 0.9562 & 0.9958 \\
\hline $11 c, 14 c, 17 c-20: 3$ & $0.06 \pm 0.05$ & $0.06 \pm 0.05$ & 0.06 & 0.9560 & 0.9958 \\
\hline $13 c, 16 c-22: 2$ & $0.04 \pm 0.02$ & $0.04 \pm 0.02$ & 0.04 & 0.9600 & 0.9962 \\
\hline $5 c, 8 c, 11 c, 14 c-20: 4$ & $0.04 \pm 0.02$ & $0.04 \pm 0.02$ & 0.04 & 0.9560 & 0.9958 \\
\hline $5 c, 8 c, 11 c, 14 c, 17 c-20: 5$ & $0.06 \pm 0.03$ & $0.06 \pm 0.03$ & 0.06 & 0.9557 & 0.9958 \\
\hline $7 c, 10 c, 13 c, 16 c, 19 c-22: 5$ & $0.08 \pm 0.01$ & $0.08 \pm 0.02$ & 0.08 & 0.9593 & 0.9961 \\
\hline ¿PUFAs cis,cis & 3.45 & 3.29 & 3.44 & & \\
\hline EPUFAs cis,trans & 2.31 & 2.22 & 2.30 & & \\
\hline ¿Total PUFAs & 5.76 & 5.51 & 5.74 & & \\
\hline ¿Total trans FAs & 7.48 & 7.14 & 7.46 & & \\
\hline ¿Total FAs & 101.54 & 95.96 & 101.05 & & \\
\hline
\end{tabular}

Mean value $\pm \operatorname{SD}(n=5)$. For abbreviations see Tables 1 and 3 .

and geometric isomers, as shown in Table 5. A very good resolution with the modified temperature program among all short chains FAs was obtained, 4:0 was completely separated from the solvent, even and odd FAs, iso-, anteiso-, cis- and trans-MUFA isomers, PUFAs, CLA isomers, were also well resolved (Figure 3).
The SFAs represented more than $60 \%$, MUFAs about $32 \%$ and PUFAs the lowest percentage at $5.7 \%$, which is characteristic of ruminant fats. SeppänenLaakso et al. (2002) indicated levels of $70 \%$ for SFAs, $25 \%$ for MUFAs, and lower amounts of $11 t$ and $11 c-18: 1$ isomers. Kramer et al. (2008) showed a wide variation in SFAs (47.03-70.51\%), 11t-18:1 
$(2.68-21.33 \%)$, total trans-18:1 (2.84-23.16\%) and cis, trans-18:2 (0.77-1.90\%).

Due to the complexity of CLA separation, combined techniques have been used in dairy and beef fats (Kramer et al., 2004). Other authors, lowering the oven temperature, improved the trans-18:1 isomer resolution, using previous $\mathrm{AgNO}_{3}$-TLC fractionation and Ag-SPE cartridges (Seppänen-Laakso et al., 2002). Related to FAME preparation, Mossoba and Kramer (2009) indicated that the derivative procedure with $\mathrm{BF}_{3}$ can produce isomers of rumenic acid. In this study, after rumenic acid, six CLA FAME isomers were detected in very small amounts of $0.02-0.05 \%$, in agreement with those described in the AOCS Method Ce 1j-07 (AOCS, 2007b).

Rozema et al. (2008) proposed modifications to the AOAC Method 996.06 (AOAC, 2005) for determining trans-FAs in butter, combining it with the AOCS Method Celh-05 (AOCS, 2005), using the same high polar capillary columns, but applying an external standard relative to $11: 0$ as IS to identify and quantify trans-18:1 and trans-18:2 isomers with a different temperature program. By this technique trans-isomers were not completely resolved and regions of trans-isomers were quantified as grouped peaks, and CLA isomers were not considered. In our work, 11:0 was identified and quantified in the butterfat sample; therefore, 13:0-TAG as IS was used, according to the AOCS Method Ce 1j-07 (2007b).

Rozema et al. (2008) reported total trans-18:1 isomers at $3.37 \%$ and trans-18:2 isomers at $0.68 \%$ for butter. These values were much lower than those determined in this study, because all the trans-FA identified in the butterfat sample were quantified separately.

Kramer et al. (2008), considering that the recommended Ag-ion separation to solve the overlapping of isomers in milk fat is time-consuming and not practical for routine analysis, assayed a GLC method using a CP Sil 88 column, combining the results of two temperature programs with a plateau at $175^{\circ} \mathrm{C}$ and another at $150{ }^{\circ} \mathrm{C}$. The results at $175^{\circ} \mathrm{C}$ were used as a quantitative reference and those obtained at $150{ }^{\circ} \mathrm{C}$ were used to correct the data. Both programs together are much longer than the modified temperature program developed in our study. The results obtained for the principal SFAs, MUFAs, PUFAs, and their respective cis- and transisomers present in this anhydrous milk fat sample were in general, within the range reported in the literature.

\section{CONCLUSIONS}

This work shows the advantages of the improved temperature program developed and applied among the five laboratories for FA analysis in some commercial fat samples compared with the one indicated in the AOCS Method Ce-1j 07 (AOCS, 2007b). Specifically, it is reproducible and allows a clear resolution of FAs, especially 4:0 from the solvent, trans18:1 from cis-18:1, 20:1 isomers from 18:3 n-3, 22:1 from 20:4 n-6, 20:5 n-3 from 24:0, and the main CLA isomers. Despite the fact that this modified temperature program is more time consuming than other programs, this proposal could be a good alternative to determine FA in samples such as soybean and sunflower mixed oil, and more complex ones such as fish oils and butterfat. In addition, for the FAME quantification of fats and oils containing a wide spectrum of FAs and their isomers, such as fish oils and ruminant dairy fats, the use of their determined correction factor ECF for each FAME, as well as the use of 13:0-TAG as IS, is recommended. In the case of edible oils like soybean and sunflower mixed oil, either the ECF or TCFr can be used as correction factor for the quantification of FAs. The temperature program proposed provides a good alternative for FA quantification for different purposes such as nutritional labeling, quality control, and research.

\section{ACKNOWLEDGEMENTS}

This work was financed by Universidad Nacional del Litoral-Cursos de Acción para la Investigación y Desarrollo (CAI + D 2009) - Secretaría de Ciencia y Técnica- UNL- Argentina and Agencia Nacional de Promoción Científica, Tecnológica y de Innovación (ANPCyT - FITS \# 001/2010) Argentina. This research was also supported with funds from CAPES, Brasil; Instituto de Nutrição Universidade Federal do Rio de Janeiro, RJ, Brasil; Faculdade de Ciências Farmacêuticas Universidade de San Paulo, SP, Brasil; INCIENSA, San José, Costa Rica and Facultad de Ciencias Químicas y Farmacéuticas, Universidad de Chile, Santiago, Chile. Finally, the authors wish to thank CYTED (Programa de Ciencia y Tecnología para el Desarrollo - Ministerio Español de Ciencia y Tecnología-BFI2002-00218) for the financial support of the Red Temática 208RT0343, where this research was integrated.

\section{REFERENCES}

AOAC. 2005. Official method 996.06. Official methods of analysis of AOAC International, 18th Ed. AOAC INTERNATIONAL, Gaithersburg, MD.

AOCS. 2005. Official method Ce 1h-05. Official methods and recommended practices of the AOCS. 6th Ed. AOCS, Champaign, IL, USA.

AOCS. 2007a. Official method Ce 1i-07. Official methods and recommended practices of the AOCS. 6th Ed. AOCS. Champaign, IL, USA.

AOCS. 2007b. Official method Ce 1j-07. Official methods and recommended practices of the AOCS. 6th Ed. AOCS, Champaign, IL, USA.

AOCS. 2011. Official Method Ce 2b-11. Official methods and recommended practices of the AOCS. 6th Ed. AOCS, Champaign, IL, USA. 
AOCS. 2011. Official Method Ce 2c-11. Official methods and recommended practices of the AOCS. 6th Ed. AOCS, Champaign, IL, USA.

Ackman RG. 1998. The year of fish oil. Chem. Indus. 3, 139-145.

Christie WW, Dobson G, Adlof RO. 2007. A practical guide to the isolation, analysis and identification of conjugated linoleic acid. Lipids 42, 1073-1084. http://dx.doi.org/10.1007/ s11745-007-3107-8.

Destaillats F, Golay PA, Joffre F, Wispelaere M, Hug B, Giuffrida F, Fauconnot L, Dionisi F. 2007. Comparison of available analytical methods to measure trans-octadecenoic acid isomeric profile and content by gas-liquid chromatography in milk fat. J. Chromatog. A 1145, 222-228. http://dx.doi. org/10.1016/j.chroma.2007.01.062.

Dionisi F, Golay PA, Fay LB. 2002. Influence of milk fat presence on the determination of trans fatty acids in fats used for infant formulae. Anal. Chim. Acta 465, 395-407. http:// dx.doi.org/10.1016/S0003-2670(02)00126-5.

Firestone D. 2006. Physical and chemical characteristics of oils, fat and waxes. 2nd Ed. AOCS Press. Champaign, IL, USA.

International Standard ISO 5509, 2000 (E). Animal and vegetable fats and oils-Preparation of methyl esters of fatty acids. 2nd Ed. International Organization for Standardization, Geneva, Switzerland.

Kramer JK, Sehat N, Dugan ME, Mossoba MM, Yurawecz MP, Roach JA, Eulitz K, Aalhus JL, Schaefer AL, Ku Y. 1998. Distribution of conjugated linoleic acid (CLA) isomers in tissue lipid classes of pigs fed a commercial CLA mixture determined by gas chromatography and silver ion-highperformance liquid chromatography. Lipids 33, 549-558. http://dx.doi.org/10.1007/s11745-998-0239-1.

Kramer JKG, Cruz-Hernández C, Deng Z, Zou J, Jahreis G, Dugan MER. 2004. Analysis of conjugated linoleic acid and trans 18:1 isomers in synthetic and animal products. Am. J. Clin. Nutr. 79, 1137S-1145S.

Kramer JKG, Hernández M, Cruz-Hernández C, Kraft J, Dugan MER. 2008. Combining results of two GC separations partly achieves determination of all cis and trans 16:1,18:1,18:2 and 18:3 except CLA isomers in milk fat as demonstrated using Ag-ion SPE fractionation. Lipids 43, 259-273. http://dx.doi.org/10.1007/s11745-007-3143-4.

Manzano P, Diego JC, Nozal MJ, Bernal JL, Bernal J. 2012. Gas chromatography-mass spectrometry approach to study fatty acid profiles in fried potato crisps. J. Food Compos. Anal. 28, 31-39. http://dx.doi.org/10.1016/j.jfca. 2012.07.003.

Mendez C, Masson L, Jiménez P. 2010. Estabilización de aceites de pescado por medio de antioxidantes naturales. Aceites Grasas 80, 270-278.

Mossoba MM, Kramer JKG. 2009. Official methods for the determination of trans fat. 2nd Edition, AOCS Press, Urbana, IL. 1-74.

Ratnayake WMN. 2004. Overview of methods for the determination of trans fatty acids by gas chromatography, silver-ion thin-layer chromatography, silver-ion liquid chromatography, and gas chromatography/mass spectrometry. J. AOAC Int. 87, 523-539.

Ratnayake WMN, Hansen S, Keneddy MP. 2006. Evaluation of the CP Sil 88 and SP-2560 GC columns used in the recently approved AOCS Official Method Ce 1h-05: determination of cis-, trans-, saturated, monounsaturated, and polyunsaturated fatty acids in vegetable or non-ruminant animal oils and fats by capillary GLC method. J. AOAC Int. 89, 475-488.

Roach JA, Yurawecz MP, Kramer JK, Mossoba MM, Eulitz $\mathrm{K}$, Ku Y. 2000. Gas chromatography-high resolution selected-ion mass spectrometric identification of trace 21:0 and 20:2 fatty acids eluting with conjugated linoleic acid isomers. Lipids 35, 797-802. http://dx.doi.org/10.1007/ s11745-000-0588-9.

Romero N, Robert P, Masson L, Luck C, Buchmann L. 1996. Composición en ácidos grasos y aporte de colesterol de conservas de jurel, sardina, salmón y atún al natural. Arch. Latinoam. Nutr. 46, 75-77.

Rozema B, Mitchell B, Winters D, Kohn A, Sullivan D, Meinholz E. 2008. Proposed modifications to AOAC 996.06, optimizing the determination of trans fatty acids: presentation of data. J. AOAC Int. 91, 92-97.

Ruiz-Rodriguez A, Reglero G, Ibañez E. 2010. Recent trends in the advanced analysis of bioactive fatty acids. J. Pharm. Biomed. Anal. 51, 305-326. http://dx.doi.org/10.1016/j.jpba. 2009.05.012.

Santercole V, Delmonte P, Kramer J. 2012. Comparison of separations of fatty acids from fish products using a 30-m Supelcowax-10 and a 100-m SP-2560 column. Lipids 47, 329-344. http://dx.doi.org/10.1007/s11745-011-3645-y.

Seppänen-Laakso T, Laakso I, Hiltunen R. 2002. Analysis of fatty acids by gas chromatography, and its relevance to research on health and nutrition. Anal. Chim. Acta 465, 39-62. http://dx.doi.org/10.1016/S0003-2670(02)00397-5.

Smith S, Hansen SL. 2008. Statistical analysis of the collaborative study in support of the Official Method AOCS Ce 1i-07: Determination of saturated, cis-monounsaturated and cis-polyunsaturated fatty acids in marine and other oils containing long chain polyunsaturated fatty acids by capillary GLC. J. AOCS Int. 85, 901-909.

Thompson M, Ellison SL, Wood R. 2006. The international harmonized protocol for the proficiency testing of analytical chemistry laboratories (IUPAC Technical Report). Pure Appl. Chem. 78, 161-163. http://dx.doi.org/10.1351/ pac200678010145.

Van de Voort FR, Ghetler A, García-González DL, Li YD. 2008. Perspectives on Quantitative Mid-FTIR Spectroscopy in Relation to Edible Oil and Lubricant Analysis: Evolution and Integration of Analytical Methodologies. Food Anal. Methods 1, 153-163. http://dx.doi.org/10.1007/ s12161-008-9031-6. 